\title{
Effects of Neuropeptide Y on Feeding Microstructure: Dissociation of Appetitive and Consummatory Actions
}

\author{
John-Paul Baird, Nora E. Gray, and Shannon G. Fischer \\ Amherst College
}

\begin{abstract}
The effects of intracerebroventricular application of Neuropeptide Y (NPY) on licking microstructure for sucrose, saccharin, and water solutions were evaluated. In Experiment 1, NPY increased meal size for three sucrose concentrations $(0.03 \mathrm{M}, 0.3 \mathrm{M}$, and $1.0 \mathrm{M})$ by increasing licking burst number but not size and by extending meals more than four-fold in duration with a slow, sustained rate of ingestion in late phases of the meal. Results are consistent with the interpretation that NPY suppressed inhibitory postingestive feedback. Experiment 2 supported this conclusion. NPY significantly increased the number of meals initiated for water, $0.1 \%$ saccharin, and $1.0 \mathrm{M}$ sucrose solutions, but meal size was only increased for 1.0 M sucrose. Therefore, NPY also increased appetitive feeding behaviors, but its consummatory effects were limited to caloric solutions. The results are discussed with regard to their potential to explain current discrepancies in the literature.
\end{abstract}

Keywords: NPY, licking, microstructure, taste, sucrose, saccharin

Intracerebroventricular (ICV) application of Neuropeptide Y (NPY) is well-known to potentiate food intake. However, discrepant and seemingly incongruent effects on the behavioral processes underlying these feeding effects have been observed within and across different test paradigms. One outstanding issue is whether NPY effects are limited to appetitive feeding behaviors. Appetitive feeding behaviors are those that bring the animal into contact with the food source (e.g., foraging), whereas consummatory feeding behaviors are ingestive acts that deliver food to the oral cavity and to the gut (Craig, 1918; Grill, 1980). Treatments that preferentially influence the size of meals are regarded to affect consummatory behavior, whereas those that modify meal frequency are considered to affect appetitive behaviors (e.g., Day, Keen-Rhinehart, \& Bartness, 2005; Kowalski, Farley, Cohen-Williams, Varty, \& Spar, 2004; Leibowitz \& Alexander, 1991; Zheng, Patterson, Phifer, \& Berthoud, 2005). Seeley, Payne, and Woods (1995) first found that ICV NPY did not potentiate intraoral intake of $0.1 \mathrm{M}$ sucrose, although NPY did increase intake of this solution in the same rats when it was offered from a bottle spout. The principal difference between these two intake paradigms is that the intraoral intake test isolates consummatory ingestive behaviors via direct infusion of the tastant into the oral cavity at an experimenter-determined rate and time of onset. It was concluded that NPY's feeding effects are therefore expressed in appetitive ingestive functions, and other laboratories have replicated this finding using a range of intraoral infusion rates $(0.5$ to $1.5 \mathrm{ml} / \mathrm{min})$ and sucrose concentrations $(0.1$

John-Paul Baird, Nora E. Gray, and Shannon G. Fischer, Department of Psychology, Amherst College.

This research was supported by Amherst College and National Institutes of Health Grant DC-05326. We thank Eric Corp and George Wade for their insightful comments on an earlier version of the manuscript.

Correspondence concerning this article should be addressed to JohnPaul Baird, Department of Psychology, Amherst College, Amherst, MA 01002. E-mail: jpbaird@amherst.edu
M to 1.0 M; Ammar et al., 2000, 2005; Benoit, Clegg, Woods, \& Seeley, 2005; Sederholm, Ammar, \& Sodersten, 2002).

These studies appear to be at odds with other findings, which suggest that NPY does increase consummatory behavior. Leibowitz and Alexander (1991) showed that NPY injection into the hypothalamic paraventricular nucleus increased the size of macronutrient meals with no accompanying increase in meal frequency, whereas Marin-Bivens, Thomas, and Stanley (1998) reported that perifornical hypothalamic NPY injections increased intake of sweetened rat chow through increases in both meal size and frequency, although most of the effect was due to the increase in meal size. In addition, ICV NPY administration has been shown to alter the rate of ingestion during a liquid sucrose meal (Lynch, Hart, \& Babcock, 1994), induce stomach relaxation (Kobashi et al., 2006), and significantly attenuate the magnitude of electrophysiological gastric distension responses in the nucleus of the solitary tract (G. J. Schwartz \& Moran, 2002). Gastric distension is well-known to suppress consummatory feeding; moreover, intraoral intake is very sensitive to gastric manipulation due to direct fill or withdrawal of nutritive and non-nutritive stimuli from the stomach (Kaplan, Siemers, \& Grill, 1994; Seeley, Grill, \& Kaplan, 1994). Finally, investigators have recently observed that NPY can increase intraoral intake, with the effect apparently dependent on baseline intake levels and degree of training (Benoit et al., 2005).

Accepting that NPY may indeed affect consummatory behaviors, we note that there is further discrepancy as to which consummatory behaviors are influenced by NPY. Initially, it was suggested that NPY increased gustatory responses because ICV NPY increased 4-hr intakes of a range of sucrose and saccharin concentrations (Lynch, Grace, Billington, \& Levine, 1993); however, intake over long-term tests can vary as a function of a combination of influences on meal frequency and/or meal size. Furthermore, meal size measures do not distinguish the differential influences of a treatment on postingestive versus gustatory feedback signals, which have separate and often opposing influences on the size of 
the meal (Davis, 1998; Davis \& Levine, 1977). Subsequently, using a more detailed analysis, Lynch et al. (1994) recorded lick counts across consecutive 10-s bins and found no effect of NPY on the rate of ingestion in the first $3 \mathrm{~min}$ of the meal (a measure of gustatory evaluation) for a sweetened milk solution. However, it is worth noting that this measure is often constrained by ceiling effects due to maximal rates of licking for palatable stimuli under baseline conditions (Spector, Klumpp, \& Kaplan, 1998), raising the question as to whether an excitatory effect NPY on gustatory evaluation was masked. Nevertheless, other evidence suggests that NPY may modify postingestive feedback from the gut: ICV NPY has been shown to suppress electrophysiological gastric distension signals, alter myoelectrical activity of the upper gastrointestinal tract, and induce gastric relaxation (Kobashi et al., 2006; G. J. Schwartz \& Moran, 2002; Thomson et al., 1993). These gastrointestinal effects of NPY could affect ingestive behavior. In their analysis, Lynch et al. (1994) observed that NPY slowed the rate of decline in ingestion rate during the meal, which is considered to indicate reduced inhibitory feedback from the gut (Davis, 1998; Davis \& Levine, 1977; Davis \& Smith, 1992). However, this analysis was not completed for an entire meal; therefore, it is unclear whether these ingestion rate effects were sustained or offset in later phases of the meal.

To address some of these unsettled questions, we performed in Experiment 1 a licking microstructure analysis of the effects of NPY on licking for a range of sucrose concentrations $(0.03,0.3$, and $1.0 \mathrm{M}$ ) in daily 90-min tests. Licking microstructure analyses can distinguish the differential influences of afferent gustatory and postingestive signals on meal-taking behavior (see Davis, 1998; Davis \& Levine, 1977; Spector et al., 1998). As noted, analysis of licking in early portions of the meal provides a measure of gustatory evaluation before the caloric and volumetric influences of ingesta develop. Recently, studies have also determined that mean size of bursts of licking within the meal also co-vary with the gustatory evaluation of tastants (Davis \& Perez, 1993; Spector et al., 1998) and that this measure is not constrained by ceiling effects on maximal lick rate. For example, increases in normally preferred sucrose concentrations produce longer bursts and increases in the initial rate of licking, whereas normally avoided concentrations of bitter quinine hydrochloride $(\mathrm{QHCl})$ produce shorter bursts in comparison with water (Hsiao \& Fan, 1993; Spector \& St. John, 1998). Furthermore, the formation of a conditioned taste aversion (CTA) to a normally preferred tastant reduces the initial rate of licking and the mean size of licking bursts as the CTA is formed (Baird, St. John, \& Nguyen, 2005). In contrast, other measures of licking appear to reflect the inhibitory influence of the postingestive load on feeding. For example, increases in the caloric or volumetric properties of food in the gut have been shown to generally produce more rapid declines in the rate of licking as the meal progresses, reductions in meal duration, and reductions in the number of bursts in the meal (Davis, 1998; Davis \& Levine, 1977; Davis, Smith, \& Kung, 1994; Davis, Smith, \& Kung, 1995; Davis, Smith, \& Sayler, 1997; Davis, Smith, \& Sayler, 1998; Eisen, Davis, Rauhofer, \& Smith, 2001; G. J. Schwartz, Salorio, Skoglund, \& Moran, 1999).

The results of Experiment 1 suggested that NPY retarded inhibitory postingestive feedback rather than enhanced gustatory evaluation. Therefore, in Experiment 2 we evaluated the effects of ICV NPY on licking for $0.1 \%$ saccharin and distilled water, as well as
1.0 $\mathrm{M}$ sucrose (to provide a replication condition). Depending on the specific mechanisms of NPY action, the response outcomes to NPY would be expected to vary across these three tastants. Should NPY affect taste evaluation, responses to noncaloric saccharin and 1.0 M sucrose, but not water, would be increased by NPY. If the effects of NPY on feeding behavior are nonspecific, then water intake would also be increased. Finally, should NPY's influence on meal size vary with caloric feedback from the gut, then only 1.0 $\mathrm{M}$ sucrose responses would be expected to increase after ICV NPY infusion.

\section{Method \\ Subjects}

Subjects were albino male Sprague-Dawley-derived rats (Charles River, Wilmington, MA) weighing $379 \pm 17 \mathrm{~g}$ on the first day of the experiment. Rats were maintained in plastic tubs with wire lids on a 12-hr light-dark schedule in a humidity- and temperature-controlled room. Food (Purina Lab Chow No. 5001, Ralston Purina, St. Louis, MO) and tap water were available ad libitum in the home cage. Rats were tested at the same time each day, between 6 and $8 \mathrm{hr}$ after lights on, in a separate room and test cage

\section{Surgery}

Rats were anesthetized with a mixture of ketamine $\mathrm{HCl}(66 \mathrm{mg} / \mathrm{kg})$ and xylazine $\mathrm{HCl}(6 \mathrm{mg} / \mathrm{kg})$. A 22-g guide cannula (Plastics 1) was stereotaxically implanted into the third ventricle (coordinates: AP $=-2.3 \mathrm{~mm}$, $\mathrm{ML}=0 \mathrm{~mm}, \mathrm{DV}=-8.5 \mathrm{~mm}$ relative to bregma) and fastened with dental acrylic and skull screws. The 28-g injection cannula extended $1 \mathrm{~mm}$ below the tip of the guide cannula, and an obturator cut flush to the guide tip was maintained in the guide at all other times. After surgical recovery, cannula placement was confirmed by assessing 30-min water intake after a cannula infusion of Angiotensin II (50 ng/5 $\mu \mathrm{l} ; 2 \mu \mathrm{l} / \mathrm{min})$. Rats that did not drink at least $5 \mathrm{ml}$ were removed from the study. Concluding behavioral experiments, cannula placements were also confirmed by ICV injection of India ink $(5 \mu \mathrm{l})$ immediately following a lethal overdose of nembutal sodium $(100 \mathrm{mg} / \mathrm{kg})$. Rats were then transcardially perfused with isotonic saline followed by $10 \%$ formalin. The brain was then removed, bisected in the mid-sagittal plane, and inspected for rostrocaudal extent of ventricular ink perfusion. Data for rats with no ink perfusion through the third and fourth ventricles were discarded

\section{Apparatus}

Rats were taken from their home cages and tested up to 8 at a time in individual plastic tubs. A drinking spout (3-mm orifice; Girton Inc., Millville, PA) was introduced to the test chamber with the spout opening positioned $4 \mathrm{~cm}$ from the floor and $1-2 \mathrm{~mm}$ behind a slit $(8 \times 28 \mathrm{~mm})$ in a metal plate attached to the front of the cage. A contact lickometer (DiLog Instruments, Tallahassee, FL) and PC were used to record licking. The computer recorded the time of each lick with 1-ms resolution. Files for each test session for each rat were saved for off-line analysis.

\section{Procedure}

\section{Habituation Training}

Rats were allowed access to the test cage daily where they were free to ingest the middle concentration in the series, $0.3 \mathrm{M}$ sucrose, for $90 \mathrm{~min}$. Habituation training continued until session intakes stabilized and exceeded $5 \mathrm{ml}$ per session. 


\section{Design}

Experiment 1. Ten habituated rats each received an NPY and an aCSF injection at each of three concentrations of sucrose tested $(0.03 \mathrm{M}, 0.3 \mathrm{M}$, and $1.0 \mathrm{M}$ ). Rats were offered the same sucrose concentration for 5 consecutive test days, with ICV injections on Days 3 and 5. This approach served to avoid potential contrast effects (Flaherty, Coppotelli, Grigson, Mitchell, \& Flaherty., 1995) and ensure stable baseline intake responses. Two rest days intervened between 5-day concentration test blocks. Concentration blocks and drug order within concentration blocks were fully counterbalanced with a Latin square.

Experiment 2. Eleven different rats were tested under conditions identical to Experiment 1, except that the taste solutions used were distilled water, $0.1 \%$ sodium saccharin, and $1.0 \mathrm{M}$ sucrose.

\section{Drug Injection}

On drug injection days, rats received a $5-\mu l$ cannula injection $(2 \mu 1 / \mathrm{min})$ of either Human Neuropeptide Y (American Peptide, Sunnyvale, CA; 5 $\mu \mathrm{g} / 1.17 \mathrm{nM}$ ) or the vehicle artificial cerebrospinal fluid (aCSF; Harvard Apparatus, Holliston, MA) 15 min prior to intake testing. Infusions were made with a 10- $\mu$ l Hamilton syringe in a microsyringe pump (KD Scientific Model 100).

\section{Data Analysis}

Data were analyzed according to previously established analysis parameters, as follows (Baird, St. John, \& Nguyen, 2005; Kaplan, Baird, \& Grill, 2001; Spector et al., 1998). Analyses of licking microstructure were limited to the first meal in the test session.

Total session intake $(\mathrm{ml})$ was measured as the difference between preand post-test weights of the spout bottle (adjusted for specific gravity of each solution). This value was then divided by the total number of licks in the session in order to yield the actual average lick volume $(\mu l)$ for each test. Meal size $(\mathrm{ml})$ was then calculated by multiplying the number of licks in the meal (first lick of the first burst to last lick of the last burst; Baird, St. John, \& Nguyen., 2005; Spector \& St. John, 1998) by the average lick volume for that session. The end of the meal was defined by a pause in licking $\geq 10 \mathrm{~min}$ (Spector et al., 1998; Zorrilla et al., 2005). Meal duration (min) was defined as the session time of the last lick in the meal minus the session time of the first lick in the meal. Average ingestion rate (licks/s) was calculated as the number of licks in the meal divided by meal duration in seconds, then multiplied by 60 to provide the average lick rate per minute.

The temporal distribution of licking was analyzed with a variety of custom-made programs (Baird, St. John, \& Nguyen, 2005; Kaplan et al., 2001). A licking burst was defined as two or more consecutive licks with no inter-lick interval (ILI) exceeding $1 \mathrm{~s}$. Thus, pauses greater than or equal to $1 \mathrm{~s}$ determined burst termination (Spector et al., 1998). Burst duration (s) was calculated by subtracting the session time of the first lick in the burst from the time of the last lick in that burst. Mean burst size (lick count) was calculated as the cumulative number of licks in all bursts in the meal divided by the number of bursts in the meal. To minimize artifact registrations due to nonlingual spout contacts, meal onset was defined as the first lick of the first burst containing at least 3 licks. Latency was defined as the time between placement of the rat into the test cage and the onset of the first burst of licking. Initial lick rate was the number of licks in the first minute of the meal.

ILIs were analyzed in several ways. The average within-burst ILI (ms) was determined by averaging all ILIs $<1 \mathrm{~s}$. Because $>95 \%$ of all ILIs in a meal are $<250 \mathrm{~ms}$ and are normally distributed below this cutoff (Davis, 1996; Spector \& St. John, 1998), the average of ILIs <250 ms was also determined. Because a second distribution of ILIs with a mode averaging twice $(\sim 320 \mathrm{~ms})$ the principal mode of the ILI distribution $(\sim 160 \mathrm{~ms})$ is also commonly observed (Baird, St. John, \& Nguyen, 2005; Davis, 1996;
Spector et al., 1998; Spector \& St. John, 1998), we evaluated the distribution of ILIs from 250 to $499 \mathrm{~ms}$. Finally, ILIs ranging from 500 to 999 $\mathrm{ms}$ were analyzed to complete analysis for the entire distribution of ILIs within bursts.

Pauses were defined as ILIs $\geq 1 \mathrm{~s}$. The mean pause duration (s) was determined as the meal duration minus the cumulative duration of bursts in the meal, divided by the number of meal pauses (which is the number of bursts minus one). Percent pause duration (\%) for the meal was the cumulative time of all pauses divided by the meal duration and multiplied by 100 . The frequency distribution of pauses was also evaluated by sorting pauses into bins of increasing temporal width. The percentage of pauses within each bin relative to the total number of pauses was also calculated.

To measure licking progress over the course of the meal, we analyzed the number of licks for each minute of each meal. Meals were also temporally divided into thirds, and the mean lick rate (licks/s converted to licks/min), mean burst duration (s), and burst count were calculated for each meal third (Baird, St. John, \& Nguyen, 2005; Spector et al., 1998; Spector \& St. John, 1998).

Responses for each measure across the 2 drug days (NPY/aCSF) at each of the 3 tastants/concentrations were compared with two-way or three-way repeated measures analyses of variance (ANOVAs) with least significant difference pairwise comparisons and paired $t$ tests to explore interactions with SPSS 11.5 software.

\section{Results}

\section{Experiment 1}

\section{Whole-Session Measures}

Both sucrose concentration and NPY significantly affected 90min session intake (Table 1). Intake varied in a classical invertedU-shaped function, with intake greatest at $0.3 \mathrm{M}$ sucrose. NPY more than doubled intake of $0.03 \mathrm{M}$ sucrose, increased intake by $58 \%$ for $0.3 \mathrm{M}$ sucrose, and nearly doubled intake of $1.0 \mathrm{M}$ sucrose (Table 1). There was no significant interaction between concentration and drug conditions, $F(2,16)=1.59, p=.23$. There was also no significant effect of NPY or sucrose concentration on the number of meals initiated in the 90 -min test period (Table 1).

\section{Meal Measures}

NPY had more pronounced effects on the first meal. Under control conditions, meal size also reflected an inverted-U-shaped function across concentrations, $F(2,16)=22.71, p<.001$. NPY significantly increased intake at all three concentrations, $F(1,8)=$ 159.36, $p<.001$, nearly doubling intake at $0.3 \mathrm{M}$ and $1.0 \mathrm{M}$ sucrose, and increasing intake almost ten-fold at $0.03 \mathrm{M}$ sucrose (see Figure 1A), though results at this concentration were variable and the Drug $\times$ Concentration interaction term was not significant, $F(2,16)=1.48, p=.26$. As there was no significant effect of either concentration, or NPY, on measured lick volumes (Table 1), a similar pattern of NPY responses was also observed for meal lick counts (Table 1).

The doubling or more of meal size by NPY across sucrose concentrations was clearly achieved in major part by prolonging the meal, as meal duration was increased on average more than four-fold by NPY at these concentrations (Figure 1B); $F(1,8)=$ $81.69, p<.001$. The increases in meal duration were observed at all concentrations, as indicated by the lack of a significant interaction, $F(2,16)=1.04, p=.38$, and the preserved shape of the 
Table 1

Licking Responses Across Sucrose Concentration and Drug Conditions

\begin{tabular}{|c|c|c|c|c|c|c|c|c|c|c|c|c|}
\hline \multirow[b]{3}{*}{ Measure } & \multicolumn{2}{|c|}{$0.03 \mathrm{M}$ sucrose } & \multicolumn{2}{|c|}{$0.3 \mathrm{M}$ sucrose } & \multicolumn{2}{|c|}{ 1.0 M sucrose } & \multicolumn{6}{|c|}{ ANOVA } \\
\hline & \multirow{2}{*}{$\frac{\mathrm{aCSF}}{\begin{array}{c}M \\
( \pm S E)\end{array}}$} & \multirow{2}{*}{$\begin{array}{c}\text { NPY } \\
M \\
( \pm S E)\end{array}$} & \multirow{2}{*}{$\begin{array}{c}\mathrm{aCSF} \\
M \\
( \pm S E)\end{array}$} & \multirow{2}{*}{ 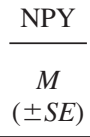 } & \multirow{2}{*}{$\begin{array}{c}\mathrm{aCSF} \\
\begin{array}{c}M \\
( \pm S E)\end{array}\end{array}$} & \multirow{2}{*}{$\begin{array}{c}\mathrm{NPY} \\
\begin{array}{c}M \\
( \pm S E)\end{array}\end{array}$} & \multicolumn{2}{|c|}{ Drug } & \multicolumn{2}{|c|}{ Conc. } & \multicolumn{2}{|c|}{ Interaction } \\
\hline & & & & & & & $F(1,8)$ & $p$ & $F(2,16)$ & $p$ & $F(2,16)$ & $p$ \\
\hline 90-min intake $(\mathrm{ml})$ & $\begin{array}{c}4.86 \\
(3.14)\end{array}$ & $\begin{array}{l}11.12 \\
(2.49)\end{array}$ & $\begin{array}{l}20.88 \\
(2.83)\end{array}$ & $\begin{array}{l}32.99 \\
(3.42)\end{array}$ & $\begin{array}{l}14.90 \\
(1.19)\end{array}$ & $\begin{array}{l}26.34 \\
(1.29)\end{array}$ & $93.09 * *$ & $<.01$ & $23.60 * *$ & $<.01$ & 1.59 & .23 \\
\hline Meals initiated & $\begin{array}{c}2.33 \\
(0.29)\end{array}$ & $\begin{array}{l}2.22 \\
(0.43)\end{array}$ & $\begin{array}{l}1.78 \\
(0.32)\end{array}$ & $\begin{array}{c}1.44 \\
(0.18)\end{array}$ & $\begin{array}{c}1.89 \\
(0.31)\end{array}$ & $\begin{array}{c}2.11 \\
(0.20)\end{array}$ & 0.37 & .56 & 2.70 & .10 & 0.45 & .65 \\
\hline 1st meal lick count & $\begin{array}{l}186 \\
(57)\end{array}$ & $\begin{array}{l}1,643 \\
(731)\end{array}$ & $\begin{array}{l}2,518 \\
(219)\end{array}$ & $\begin{array}{l}5,238 \\
(593)\end{array}$ & $\begin{array}{l}1,785 \\
(183)\end{array}$ & $\begin{array}{l}4,089 \\
(423)\end{array}$ & $79.21 * *$ & $<.01$ & $16.68^{* *}$ & $<.01$ & 0.80 & .47 \\
\hline Lick volume $(\mu 1)$ & $\begin{array}{c}4.95 \\
(0.30)\end{array}$ & $\begin{array}{c}6.75 \\
(0.83)\end{array}$ & $\begin{array}{c}5.76 \\
(0.77)\end{array}$ & $\begin{array}{c}5.96 \\
(0.33)\end{array}$ & $\begin{array}{c}4.91 \\
(0.34)\end{array}$ & $\begin{array}{c}5.92 \\
(0.35)\end{array}$ & 4.96 & .06 & 0.50 & .62 & 2.05 & .16 \\
\hline Latency (s) & $\begin{array}{l}64.11 \\
(23.14)\end{array}$ & $\begin{array}{l}43.35 \\
(30.68)\end{array}$ & $\begin{array}{c}9.40 \\
(3.82)\end{array}$ & $\begin{array}{c}6.62 \\
(1.59)\end{array}$ & $\begin{array}{l}13.94 \\
(3.22)\end{array}$ & $\begin{array}{c}3.30 \\
(0.70)\end{array}$ & 2.49 & .15 & 2.78 & .09 & 0.56 & .58 \\
\hline 1st min lick rate & $\begin{array}{c}54 \\
(15)\end{array}$ & $\begin{array}{l}122 \\
(36)\end{array}$ & $\begin{array}{l}238 \\
(28)\end{array}$ & $\begin{array}{l}284 \\
(12)\end{array}$ & $\begin{array}{l}268 \\
(31)\end{array}$ & $\begin{array}{l}317 \\
(28)\end{array}$ & $7.10 *$ & .03 & $27.67 * *$ & $<.01$ & 0.01 & .93 \\
\hline $\begin{array}{l}\text { Mean ingestion rate } \\
\text { (licks/min) }\end{array}$ & $\begin{array}{l}147 \\
(54)\end{array}$ & $\begin{array}{c}99 \\
(17)\end{array}$ & $\begin{array}{l}161 \\
(21)\end{array}$ & $\begin{array}{l}114 \\
(18)\end{array}$ & $\begin{array}{l}199 \\
(19)\end{array}$ & $\begin{array}{l}143 \\
(24)\end{array}$ & $7.79 *$ & .02 & 1.03 & .38 & 0.02 & .99 \\
\hline Mean burst size (licks) & $\begin{array}{l}40 \\
(7)\end{array}$ & $\begin{array}{l}42 \\
(6)\end{array}$ & $\begin{array}{l}105 \\
(12)\end{array}$ & $\begin{array}{l}80 \\
(18)\end{array}$ & $\begin{array}{l}136 \\
(20)\end{array}$ & $\begin{array}{l}70 \\
(7)\end{array}$ & $6.38 *$ & .04 & $11.02 * *$ & $<.01$ & $4.19 *$ & .03 \\
\hline Mean burst duration (s) & $\begin{array}{c}5.61 \\
(1.03)\end{array}$ & $\begin{array}{c}6.50 \\
(0.95)\end{array}$ & $\begin{array}{l}15.51 \\
(1.64)\end{array}$ & $\begin{array}{l}12.11 \\
(2.93)\end{array}$ & $\begin{array}{l}19.41 \\
(3.12)\end{array}$ & $\begin{array}{l}10.35 \\
(1.08)\end{array}$ & $5.22 *$ & .05 & $9.83 * *$ & $<.01$ & $3.95^{*}$ & .04 \\
\hline $\begin{array}{l}\text { Within-burst lick rate } \\
\text { (licks/s) }\end{array}$ & $\begin{array}{c}6.64 \\
(0.17)\end{array}$ & $\begin{array}{l}6.06 \\
(0.25)\end{array}$ & $\begin{array}{c}6.59 \\
(0.24)\end{array}$ & $\begin{array}{c}6.43 \\
(0.07)\end{array}$ & $\begin{array}{c}6.90 \\
(0.13)\end{array}$ & $\begin{array}{c}6.65 \\
(0.16)\end{array}$ & $12.73 * *$ & .01 & 2.51 & .11 & 1.51 & .25 \\
\hline Mean pause duration (s) & $\begin{array}{l}52.44 \\
(28.56)\end{array}$ & $\begin{array}{l}28.63 \\
(7.47)\end{array}$ & $\begin{array}{l}27.95 \\
(4.30)\end{array}$ & $\begin{array}{l}29.21 \\
(4.69)\end{array}$ & $\begin{array}{l}26.14 \\
(6.25)\end{array}$ & $\begin{array}{l}26.75 \\
(6.72)\end{array}$ & 0.67 & .44 & 0.77 & .48 & 0.48 & .63 \\
\hline Pause time $(\%)$ & $\begin{array}{c}75 \\
(10)\end{array}$ & $\begin{array}{l}73 \\
(5)\end{array}$ & $\begin{array}{l}61 \\
(5)\end{array}$ & $\begin{array}{l}70 \\
(5)\end{array}$ & $\begin{array}{l}52 \\
(5)\end{array}$ & $\begin{array}{l}68 \\
(6)\end{array}$ & 4.31 & .08 & 1.33 & .30 & 1.51 & .26 \\
\hline
\end{tabular}

Note. $\quad$ ANOVA $=$ analysis of variance; $\mathrm{aCSF}=$ artificial cerebrospinal fluid; $\mathrm{NPY}=$ neuropeptide $\mathrm{Y}$; conc. $=$ concentration.

$* p<.05 . \quad * * p<.01$.

concentration-duration function under NPY conditions (see Figure 1B), $F(2,16)=4.07, p<.04$.

A doubling of intake by NPY accompanied by a four-fold increase in meal duration indicates that contrary to expectations, NPY produced a slower overall average ingestion rate. NPY reduced the average rate of ingestion by 25 to $30 \%$ across sucrose concentrations (Table 1). To explore the basis of this rate effect, we evaluated the distribution of licking within and across bursts and across phases of the meal.

\section{Licking Microstructure}

NPY significantly slowed the average rate of licking within bursts, albeit by a very small proportion (3\%; see Figure 2). Analysis of ILIs in the primary ILI $(0-250 \mathrm{~ms})$ distribution indicated that NPY did not affect the principal rate of licking. Rather, there was a small but significant increase in the proportion of longer ILIs in the $500 \mathrm{~ms}$ to $999 \mathrm{~ms}$ range, which are commonly considered to represent missed licks or brief oromotor movements, such as tongue protrusions or possibly gapes (Figure 2; Davis, 1996; Travers, Dinardo, \& Karimnamazi, 1997). There were no significant differences in mean within-burst lick rates across concentrations (Table 1) and no effects of NPY on any other measures of within-burst licking (see Figure 2).

Contrary to the negligible effects of NPY on the rate of licking within bursts, NPY did affect the size and, more profoundly, the number of licking bursts in the meal. Consistent with previous studies, the length of bursts, whether measured by duration or size, increased significantly and positively with sucrose concentration under control conditions (Figure 3A; Table 1). However, NPY did not further increase burst length. Indeed, NPY significantly halved burst length/duration at $1.0 \mathrm{M}$ sucrose, with little influence at the lower two concentrations (see Figure 3A). This conclusion is supported by significant interaction terms (see Table 1) and paired comparisons significant only for the $1.0 \mathrm{M}$ sucrose condition $(p s<.02)$. The effect of NPY to increase the number of licks in the meal therefore had to be achieved through an increase in the burst count (given that the product of burst count and mean burst size closely approximates meal lick count). Indeed, NPY increased the number of bursts at all concentrations by four-fold or more: drug, $F(1,8)=23.26, p<.001$; concentration, $F(2,16)=3.41$, $p=.06$; interaction, $F(2,16)=0.30, p=.74$; see Figure 3B.

The long extension of meal duration by NPY could have been due to increases in the duration of pauses between bursts. However, there were no significant effects of either NPY or sucrose concentration on the mean duration of pauses between bursts or on the proportion of meal time spent in pauses (Table 1). Furthermore, NPY had no effect on the relative distribution of pauses in the meal. Although pause counts were increased by NPY (as burst counts were increased four-fold), they were increased uniformly across the pause range distribution at all concentrations ( $p \mathrm{~s}>.05$; see Figure 4 for example). Supporting this observation, there were no differences in the proportional frequencies of pause ranges 
A
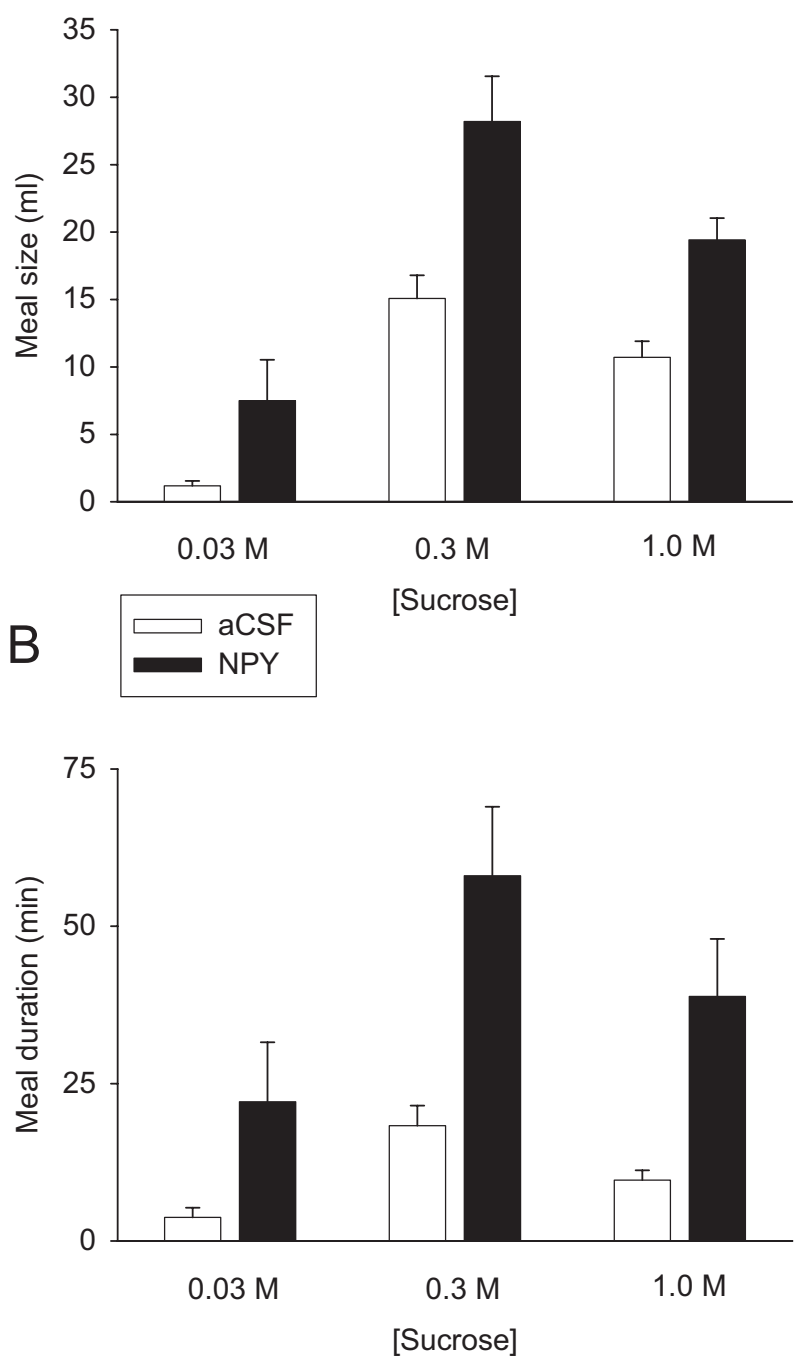

Figure 1. (A) Mean (plus standard error) meal size (ml) values for rats treated with artificial cerebrospinal fluid (aCSF; open bars) and Neuropeptide Y (NPY; filled bars) at all three sucrose concentrations $(0.03 \mathrm{M}, 0.3 \mathrm{M}$, and $1.0 \mathrm{M})$. NPY significantly doubled intake or more at all concentrations. (B) Mean (plus standard error) meal duration ( $\mathrm{min}$ ) values for aCSF-treated (open bars) and NPY-treated (filled bars) rats at all three sucrose concentrations $(0.03 \mathrm{M}, 0.3 \mathrm{M}$, and $1.0 \mathrm{M})$. NPY significantly prolonged the meal at least four-fold at all concentrations.

between NPY and aCSF conditions at any concentration ( $p \mathrm{~s}>$ .08 ; see Figure 4B). Therefore, the meal lengthening effect of NPY was produced by the creation of additional bursts of licking and their attendant pauses, whether short or long.

\section{Meal Dynamics}

Overall, the analysis of ingestion across phases of the meal revealed a two-part effect of NPY on meal taking. As indicated below, NPY at first increased ingestion rate early in the meal; it then extended the meal with a slow but sustained ingestion rate.
As previously established (Davis \& Perez 1993; Spector et al., 1998), the initial rate of ingestion (1st min) significantly increased across sucrose concentrations under control conditions (see Figure 5 and Table 1). NPY also produced a relatively small but statistically significant $30 \%$ increase in the rate of licking in the 1 st min that was relatively uniform across concentrations, as supported by the lack of a significant interaction term (Table 1).

The Lick $\times$ Minute group curves depicted in Figure 5 clearly suggest that NPY increased the rate of ingestion in early portions of the meal and that NPY prolonged meal duration. Because the

A

$1 \mathrm{M}$ Sucrose

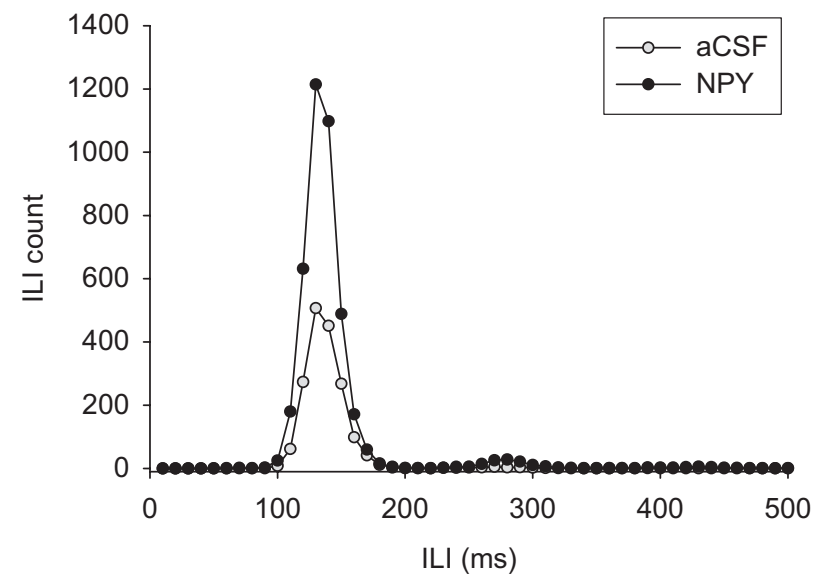

B

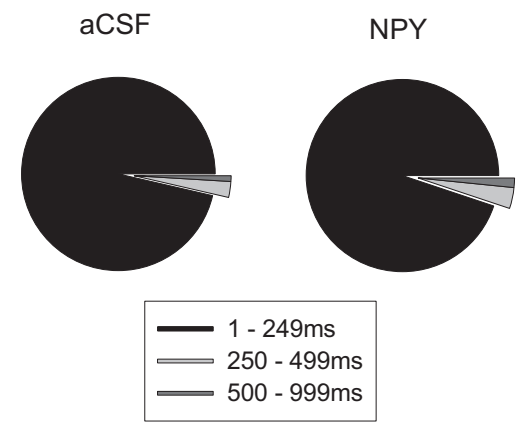

Figure 2. Comparison of within-burst licking measures for artificial cerebrospinal fluid (aCSF)- and Neuropeptide Y (NPY)-treated rats. Overall, NPY had little effect on the rate of licking within bursts. (A) Frequency distribution of inter-lick intervals (ILIs) $<500 \mathrm{~ms}$ (10-ms bins) for rats ingesting 1.0 M sucrose under NPY and aCSF treatment conditions. Although NPY increased the number of licks within meals (hence the number of ILIs), NPY had no significant effect on the mean duration (ms) or relative distribution of ILIs $<500 \mathrm{~ms}$, which accounted for more than 95\% of all ILIs in the meal. (B) Mean proportion (\%) of ILIs within bursts in aCSF- (left) and NPY- (right) treated rats, across three time ranges. Results are collapsed across concentrations, as there was no difference among concentrations. In NPY-treated rats, there was a very small but statistically significant 3\% increase in the proportion of $500 \mathrm{~ms}$ to $999 \mathrm{~ms}$ ILIs in bursts. 
A

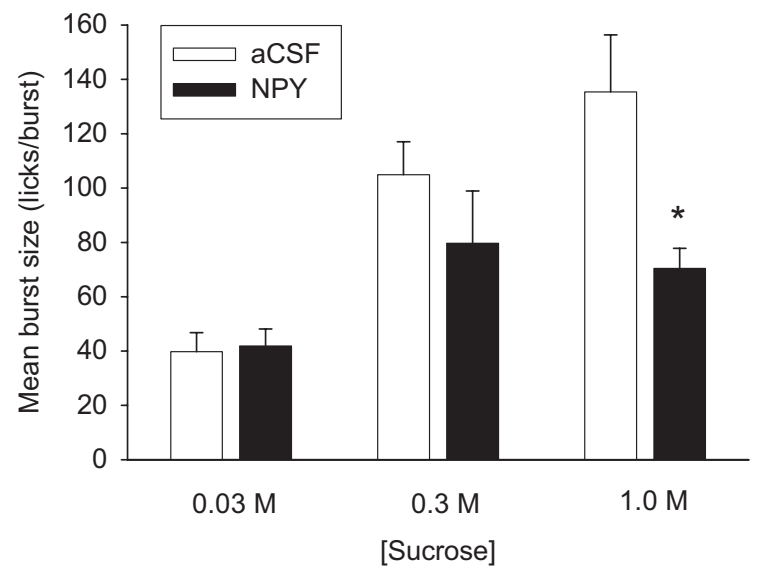

B

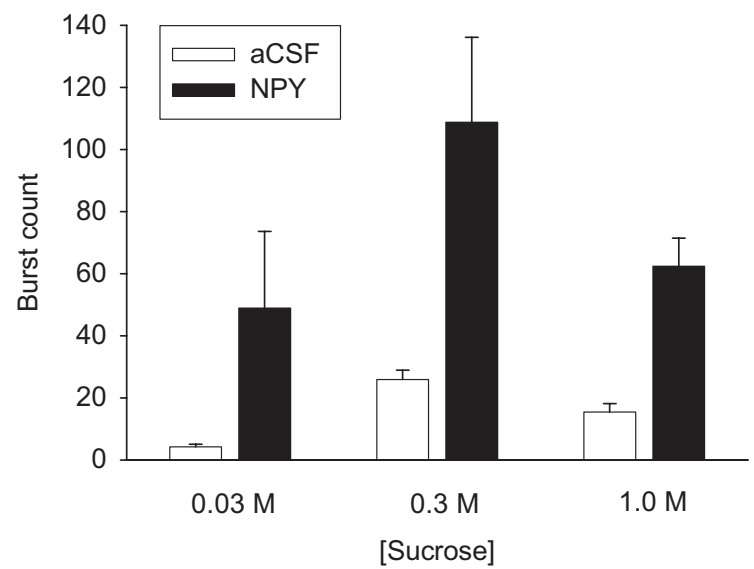

Figure 3. Comparison of burst measures for artificial cerebrospinal fluid (aCSF)- and Neuropeptide Y (NPY)-treated rats. (A) Mean (plus standard error) burst size (licks/burst) for aCSF-treated (open bars) versus NPYtreated (filled bars) rats. Burst size increased monotonically with sucrose concentration in aCSF-treated rats; however, NPY treatment significantly halved mean burst size at the $1.0 \mathrm{M}$ sucrose condition. $* p<.02$. (B) Mean (plus standard error) number of bursts in the meal was more than quadrupled for NPY-treated (filled bars) relative to aCSF-treated (open bars) rats.

group curves depicted in Figure 5 include subject attrition (Baird, Kaplan, \& Grill, 1999; Kaplan et al., 2001), we explored the effects of NPY in early portions of the meal by limiting statistical analysis of the minute-by-minute lick rate to the first $5 \mathrm{~min}$ of $0.3 \mathrm{M}$ and $1.0 \mathrm{M}$ sucrose meals, meal portions for sucrose concentrations for which all rats were actively ingesting. NPY significantly increased the rate of licking in the first $5 \mathrm{~min}$ at both the $0.3 \mathrm{M}, F(1,8)=7.24, p<.03$, and $1.0 \mathrm{M}, F(1,8)=$ $6.29, p<.04$, sucrose concentrations. There were no significant main effects for the minutes term at either concentration (indicating no decline in lick rate over this period) and no significant interaction terms (all $p \mathrm{~s}>.26$ ).

Although NPY significantly increased lick rate, we deduced that this effect was likely limited to early phases of the test meal, as the average ingestion rate overall was suppressed by
NPY (see Table 1), suggesting that initial lick rate increases must have been offset by a slower rate of ingestion in later portions of the NPY-protracted meal. This inference was supported by the meal-thirds analysis: Figure 6 shows that although the rate of licking declined across subsequent meal thirds in most conditions, $F(2,16)=24.91, p<.001$ NPY further suppressed the rate of licking in the last one third of the meal relative to controls, at

A

$0.3 \mathrm{M}$ Sucrose
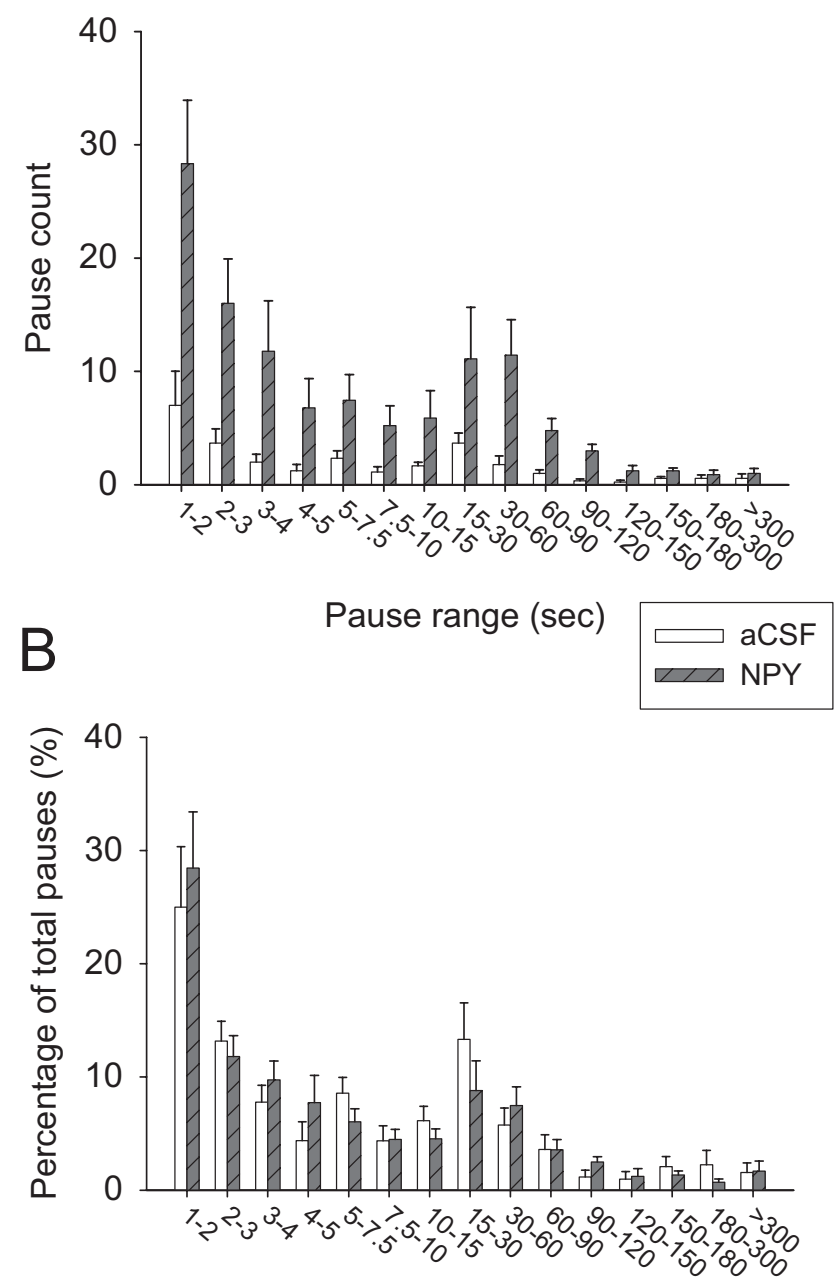

Pause range (sec)

Figure 4. (A) Frequency distribution of pauses for Neuropeptide Y (NPY)-treated rats (hatched bars) and artificial cerebrospinal fluid (aCSF)treated rats (open bars) ingesting $0.3 \mathrm{M}$ sucrose. Mean (plus standard error) pause counts in each pause range are plotted. Range labels have been simplified for clarity of presentation. Range categories include pauses equal to or greater than the lower value through pauses up to $1 \mathrm{~ms}$ less than the upper value indicated. For example, category 15-30 s includes pauses $>15,000 \mathrm{~ms}$ through $29,999 \mathrm{~ms}$. Although NPY significantly increased the number of pauses in the meal, these increases were uniform across the entire pause distribution. This is indicated in (B), which shows the same data as in (A), except that pause counts in each range are plotted as a proportion (\%) of all pauses in the meal. 

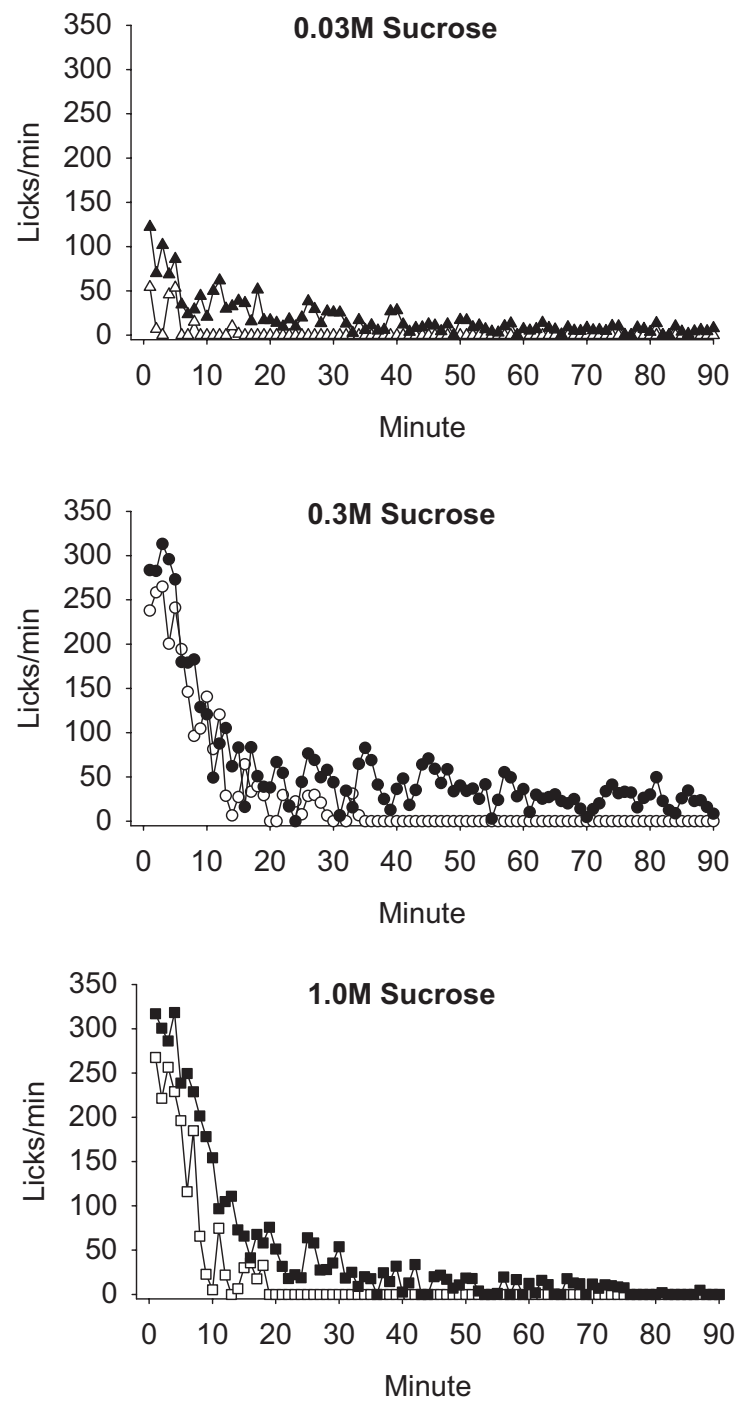

Figure 5. Mean ingestion rates (licks/min) for artificial cerebrospinal fluid (aCSF; open symbols) versus Neuropeptide Y (NPY; filled symbols) drug conditions in rats ingesting $0.03 \mathrm{M}$ sucrose (top panel), $0.3 \mathrm{M}$ sucrose (middle panel), and 1.0 M sucrose concentrations (bottom panel) for each minute of the testing session.

$0.3 \mathrm{M}$ and 1.0 $\mathrm{M}$ sucrose concentrations. This is supported by a significant Meal Third $\times$ Drug interaction, $F(2,16)=3.87, p<.04$.

Figure 7A shows that NPY systematically increased both the number of bursts in the meal and the meal duration. The increases in burst count were uniform across meal phases, as also indicated by a nonsignificant Drug $\times$ Meal Third interaction, $F(2,16)=3.00, p<.08$. Recall that NPY significantly reduced mean burst duration for the whole meal at the $1.0 \mathrm{M}$ sucrose concentration (Figure 4). Figure 7B shows that under NPY, burst duration tended to decline as meals grew very lengthy at the $0.3 \mathrm{M}$ and $1.0 \mathrm{M}$ concentrations, whereas bursts showed little change or a tendency to increase under control conditions. This conclusion is supported by significant Meal Third $\times$ Drug, $F(2,16)=9.30, p<.001$, and Concentration $\times$ Drug, $F(2,16)=6.00, p<.01$, interactions.
Experiment 2

\section{Session Measures}

As observed in Experiment 1, NPY reliably increased intake of 1.0 M sucrose, but surprisingly there was no significant effect of NPY on 90-min saccharin or water intake (see Table 2). The orexigenic effect of NPY was clearly limited to the sucrose con-
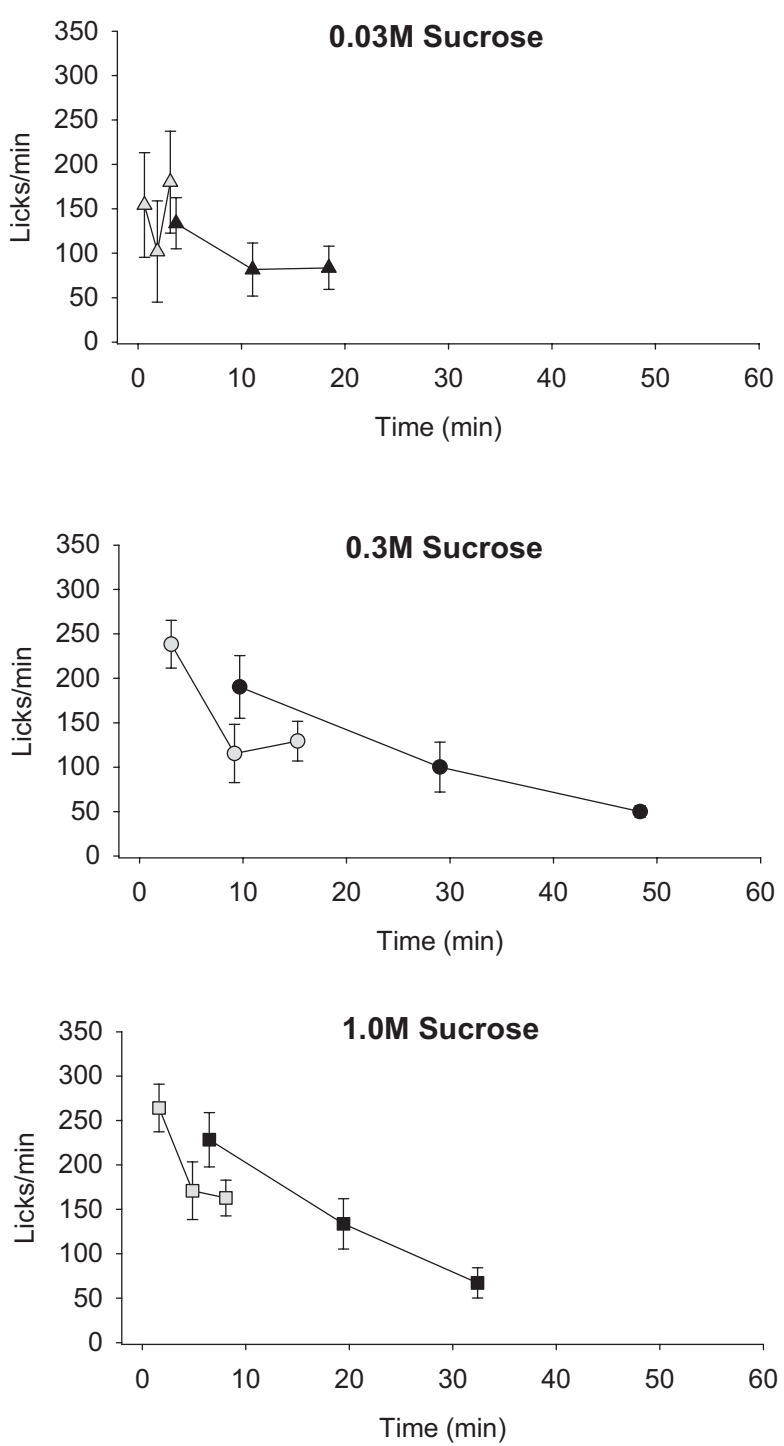

Figure 6. Mean (plus or minus standard error) licking rate (licks/min) across meal thirds for rats treated with Neuropeptide Y (NPY; filled symbols) and artificial cerebrospinal fluid (aCSF; open symbols). Meals were temporally divided into thirds, and the mean ingestion rates (licks/ min) associated with each meal third are presented for rats ingesting 0.03 $\mathrm{M}$ sucrose (A), 0.3 M sucrose (B), and 1.0 M sucrose (C). The mean lick rate for each meal third is plotted at the temporal midpoint of each meal third (i.e., at 1/6th, 3/6ths, and 5/6ths of the average meal duration); it should be noted that all meals begin at the same time, Minute 1. The figure shows that for all sucrose concentrations, NPY significantly prolonged meals with a significantly slower rate of ingestion in the final third of the meal compared with aCSF control conditions. 


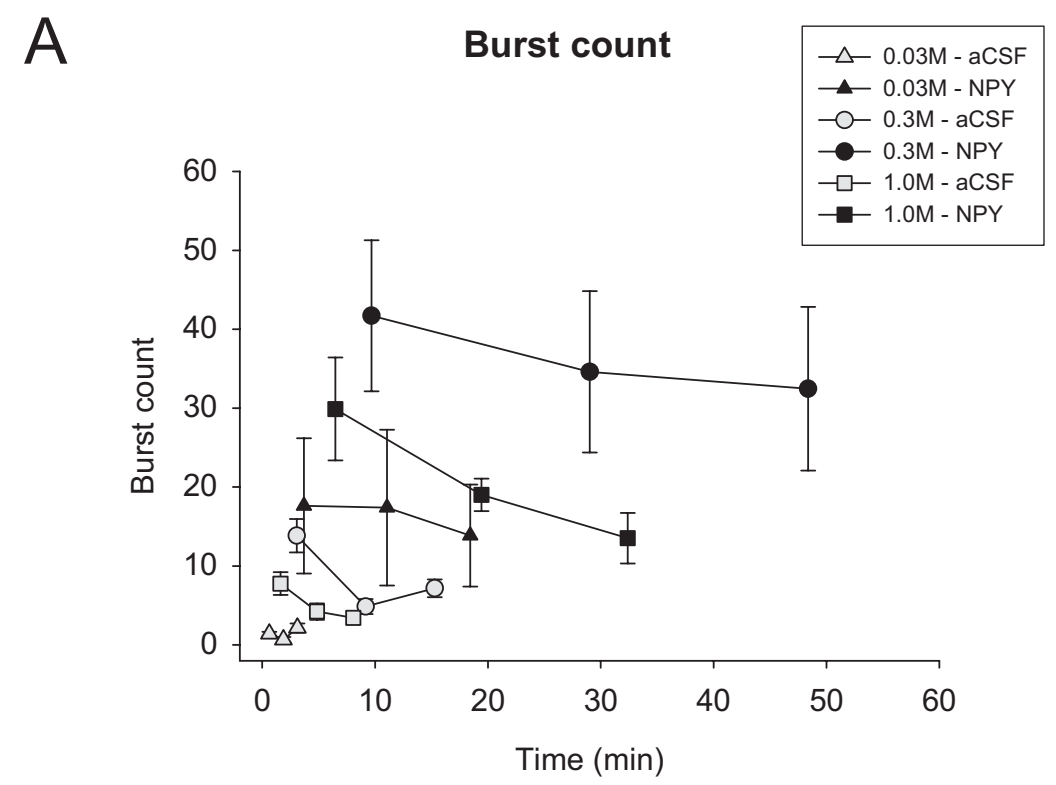

B

Burst Duration
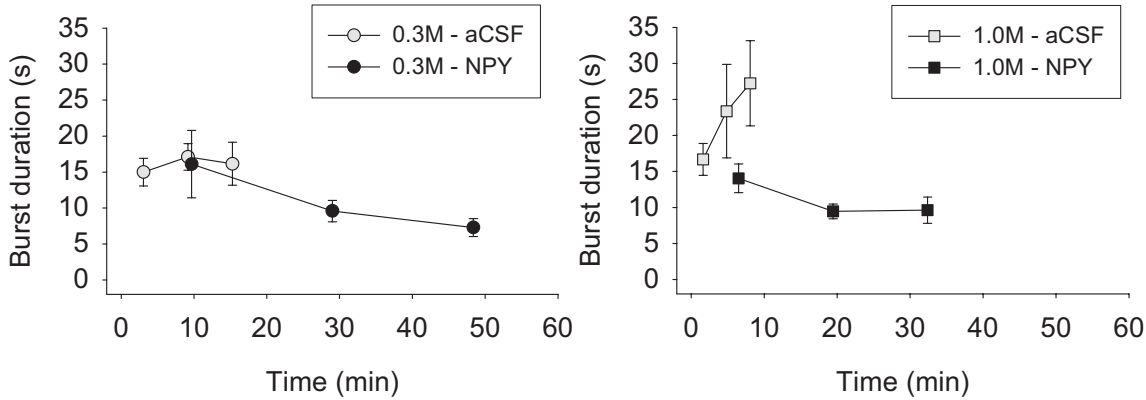

Figure 7. Comparison of burst measures across meal thirds for rats treated with Neuropeptide Y (NPY; filled symbols) and artificial cerebrospinal fluid (aCSF; open symbols). Meals were temporally divided into thirds, and the mean (plus or minus standard error) number of bursts and the mean burst duration (s) associated with each meal third are presented. The mean for each meal third is plotted at the temporal midpoint of each meal third (i.e., at 1/6th, 3/6ths, and 5/6ths of the average meal duration); it should be noted that all meals begin at the same time, Minute 1. (A) NPY increased the number of bursts in the meal in a manner that was evenly distributed across meal thirds $(0.03 \mathrm{M}=0.03 \mathrm{M}$ sucrose; $0.3 \mathrm{M}=0.3 \mathrm{M}$ sucrose; $1.0 \mathrm{M}=1.0 \mathrm{M}$ sucrose). (B) The duration of bursts tended to decline or remain constant across meal thirds $(0.3 \mathrm{M}=0.3 \mathrm{M}$ sucrose; $1.0 \mathrm{M}=1.0 \mathrm{M}$ sucrose).

dition, as supported by a robust Drug $\times$ Tastant interaction (Table 2 ) and paired comparisons (sucrose, $p<.001$; saccharin, $p>.09$ ). NPY also significantly increased the number of meals initiated in the session for all three tastants, as indicated by a significant main effect of drug with no significant interaction (Figure 8B): drug, $\mathrm{F}(1,10)=7.57, p<.02 ;$ tastant, $\mathrm{F}(2,20)=0.17, p=.84 ;$ Drug $\times$ Tastant interaction: $\mathrm{F}(2,20)=0.03, p<.98)$.

\section{Whole-Meal Measures and Licking Microstructure}

Although the changes in saccharin intake for the 90-min session were not statistically significant, mean intake was notably in- creased by $43 \%$ under NPY conditions. However, when analysis was restricted to the first meal in the test session, this effect was entirely lost; saccharin meal size varied by only $5 \%$ under NPY conditions (see Figure 8A). Therefore, most of the $43 \%$ increase in saccharin session intake was due to the increase in meal frequency.

Under 1.0 M sucrose conditions, virtually all of the significant effects of NPY observed for this taste solution in Experiment 1 were replicated: Meal size was approximately doubled (Figure $8 ; p<.02$ ), meal duration and burst counts were nearly quadrupled (Figure 9; $p \mathrm{~s}<.05$ ), burst size was halved (Table 2 and Figure 9), the rate of licking within bursts was slightly 
Table 2

Licking Responses Across Tastant and Drug Conditions

\begin{tabular}{|c|c|c|c|c|c|c|c|c|c|c|c|c|}
\hline \multirow[b]{3}{*}{ Measure } & \multicolumn{2}{|c|}{ Water } & \multicolumn{2}{|c|}{$0.1 \%$ Saccharin } & \multicolumn{2}{|c|}{ 1.0 M Sucrose } & \multicolumn{6}{|c|}{ ANOVA } \\
\hline & \multirow{2}{*}{$\begin{array}{c}\mathrm{aCSF} \\
\begin{array}{c}M \\
( \pm S E)\end{array}\end{array}$} & \multirow{2}{*}{$\begin{array}{c}\mathrm{NPY} \\
\begin{array}{c}M \\
( \pm S E)\end{array}\end{array}$} & \multirow{2}{*}{ 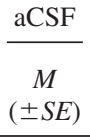 } & \multirow{2}{*}{ 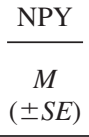 } & \multirow{2}{*}{$\begin{array}{c}\frac{\mathrm{aCSF}}{M} \\
( \pm S E)\end{array}$} & \multirow{2}{*}{ 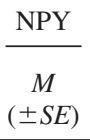 } & \multicolumn{2}{|c|}{ Drug } & \multicolumn{2}{|c|}{ Conc. } & \multicolumn{2}{|c|}{ Interaction } \\
\hline & & & & & & & $F(1,10)$ & $p$ & $F(2,20)$ & $p$ & $F(2,20)$ & $p$ \\
\hline 90-min intake $(\mathrm{ml})$ & $\begin{array}{c}4.23 \\
(0.69)\end{array}$ & $\begin{array}{c}3.03 \\
(0.48)\end{array}$ & $\begin{array}{l}11.92 \\
(2.96)\end{array}$ & $\begin{array}{l}17.03 \\
(2.45)\end{array}$ & $\begin{array}{l}16.27 \\
(2.86)\end{array}$ & $\begin{array}{l}31.14 \\
(4.02)\end{array}$ & $12.94 * *$ & .01 & $31.09 * *$ & $<.01$ & $14.83^{* * \mathrm{c}}$ & $<.01$ \\
\hline 1st meal lick count & $\begin{array}{c}401 \\
(113)\end{array}$ & $\begin{array}{l}263 \\
(75)\end{array}$ & $\begin{array}{l}1,304 \\
(289)\end{array}$ & $\begin{array}{l}1,448 \\
(337)\end{array}$ & $\begin{array}{l}1,634 \\
(188)\end{array}$ & $\begin{array}{l}3,276 \\
(530)\end{array}$ & $9.12 * *$ & .01 & $20.67 * *$ & $<.01$ & $6.41 * * \mathrm{c}$ & .01 \\
\hline Lick volume $(\mu \mathrm{l})$ & $\begin{array}{c}6.26 \\
(0.58)\end{array}$ & $\begin{array}{c}6.16 \\
(0.98)\end{array}$ & $\begin{array}{c}6.34 \\
(0.38)\end{array}$ & $\begin{array}{c}5.61 \\
(0.23)\end{array}$ & $\begin{array}{c}6.85 \\
(0.53)\end{array}$ & $\begin{array}{c}5.64 \\
(0.32)\end{array}$ & 2.25 & .18 & 0.62 & .55 & 0.24 & .79 \\
\hline Latency (s) & $\begin{array}{c}1,346 \\
(1,267)\end{array}$ & $\begin{array}{l}46 \\
(25)\end{array}$ & $\begin{array}{l}35 \\
(9)\end{array}$ & $\begin{array}{c}6 \\
(2)\end{array}$ & $\begin{array}{c}9 \\
(4)\end{array}$ & $\begin{array}{c}5 \\
(2)\end{array}$ & 1.10 & .32 & 1.18 & .33 & 1.02 & .38 \\
\hline 1st min lick rate & $\begin{array}{c}99 \\
(27.22)\end{array}$ & $\begin{array}{l}38 \\
(16)\end{array}$ & $\begin{array}{l}209 \\
(37)\end{array}$ & $\begin{array}{l}176 \\
(37)\end{array}$ & $\begin{array}{l}227 \\
(27)\end{array}$ & $\begin{array}{l}283 \\
(19)\end{array}$ & 0.39 & .55 & $25.53 * *$ & $<.01$ & $3.91 * a, c$ & .04 \\
\hline $\begin{array}{l}\text { Mean ingestion rate (licks/ } \\
\text { min) }\end{array}$ & $\begin{array}{l}155 \\
(59)\end{array}$ & $\begin{array}{c}192 \\
(121)\end{array}$ & $\begin{array}{l}95 \\
(16)\end{array}$ & $\begin{array}{c}85 \\
(20)\end{array}$ & $\begin{array}{l}170 \\
(23)\end{array}$ & $\begin{array}{l}145 \\
(26)\end{array}$ & 0.00 & .97 & 1.20 & .32 & 0.18 & .84 \\
\hline Mean burst size (licks) & $\begin{array}{l}33 \\
(9)\end{array}$ & $\begin{array}{l}29 \\
(9)\end{array}$ & $\begin{array}{l}61 \\
(16)\end{array}$ & $\begin{array}{l}43 \\
(9)\end{array}$ & $\begin{array}{l}122 \\
(33)\end{array}$ & $\begin{array}{c}60 \\
(11)\end{array}$ & 4.20 & .07 & $10.45^{* *}$ & $<.01$ & $3.45^{* \mathrm{c}}$ & .05 \\
\hline Mean burst duration (s) & $\begin{array}{c}5.21 \\
(1.45)\end{array}$ & $\begin{array}{c}4.28 \\
(1.38)\end{array}$ & $\begin{array}{c}9.24 \\
(2.59)\end{array}$ & $\begin{array}{c}6.86 \\
(1.55)\end{array}$ & $\begin{array}{l}18.57 \\
(4.91)\end{array}$ & $\begin{array}{c}9.44 \\
(1.72)\end{array}$ & 4.26 & .07 & $11.86 * *$ & $<.01$ & 2.96 & .08 \\
\hline Within-burst lick rate (licks/s) & $\begin{array}{l}5.95 \\
(0.26)\end{array}$ & $\begin{array}{c}5.64 \\
(0.27)\end{array}$ & $\begin{array}{c}6.34 \\
(0.31)\end{array}$ & $\begin{array}{c}5.97 \\
(0.21)\end{array}$ & $\begin{array}{c}6.75 \\
(0.13)\end{array}$ & $\begin{array}{c}6.31 \\
(0.10)\end{array}$ & $18.50^{* *}$ & .01 & $5.92 * *$ & .01 & 0.01 & .99 \\
\hline Mean pause duration (s) & $\begin{array}{l}25.16 \\
(7.79)\end{array}$ & $\begin{array}{l}31.18 \\
(8.71)\end{array}$ & $\begin{array}{l}34.50 \\
(7.13)\end{array}$ & $\begin{array}{l}34.48 \\
(9.03)\end{array}$ & $\begin{array}{c}30.57 \\
(10.12)\end{array}$ & $\begin{array}{l}19.28 \\
(5.12)\end{array}$ & 0.05 & .82 & 0.84 & .45 & 0.59 & .56 \\
\hline Pause time $(\%)$ & $\begin{array}{c}62.89 \\
(11.33)\end{array}$ & $\begin{array}{c}67.31 \\
(10.57)\end{array}$ & $\begin{array}{l}75.94 \\
(4.53)\end{array}$ & $\begin{array}{l}77.23 \\
(5.14)\end{array}$ & $\begin{array}{l}57.16 \\
(5.49)\end{array}$ & $\begin{array}{l}61.02 \\
(6.35)\end{array}$ & 0.36 & .56 & 2.74 & .09 & 0.03 & .97 \\
\hline
\end{tabular}

Note. $\quad$ ANOVA $=$ analysis of variance; $\mathrm{aCSF}=$ artificial cerebrospinal fluid; $\mathrm{NPY}=$ neuropeptide-Y; conc. $=$ concentration. A lowercase superscript letter indicates a significant NPY-aCSF pairwise comparison for the following tastants: a, water; b, saccharin; and c, sucrose.

$* p<.05 . \quad * * p<.01$.

slower (Table 2), and the initial rate of licking was significantly increased by $25 \%$ (Table 2 ).

For the water and saccharin conditions, no effects of NPY were observed for any microstructural features, except that the initial rate of licking for water was significantly reduced by NPY (see Table 2).

\section{Meal Dynamics}

The effects of NPY across phases of the 1.0 M sucrose meal also replicated those observed in Experiment 1; most of the pertinent statistical tests that met significance in Experiment 1 were also met in Experiment $2(p s<.05$; see Experiment 1 for description of these comparisons). One exception was that the Meal Third $\times$ Drug interaction for lick rate across meal thirds was no longer statistically significant, $F(2,20)=1.46, p=.26$. This was most likely due to the lack of NPY effect on the water and saccharin conditions, as the pattern of these responses for the sucrose condition was comparable to Experiment 1, with the rate of licking in the final meal third under NPY less than two thirds that for the control condition (data not shown). Overall, there was no effect of NPY on the temporal distribution of saccharin or water ingestion over the course of the test meal, as there was no significant effect of NPY on any of the measures of meal progress reported in Experiment 1 (all $p s>.11$ for the comparable statistical tests).

\section{Discussion}

In this study, 3V NPY injection increased intake of $0.03 \mathrm{M}$, $0.3 \mathrm{M}$, and $1.0 \mathrm{M}$ sucrose in 90 -min tests, the broadest range of sucrose concentrations for which NPY has been reported to increase intake. Although NPY also produced a nonsignificant $43 \%$ increase in $0.1 \%$ saccharin intake in the 90 -min test, this increase for saccharin was completely lost, whereas sucrose meal sizes were increased when the analysis was restricted to the first meal (see Figures 1 and 8). Thus, NPY clearly affected consummatory feeding, as indicated by increased single meal sizes, but this effect occurred only for sucrose, not saccharin or water.

NPY also increased appetitive behavior but in a manner that was dissociated from its effects on meal size. In Experiment 2, the number of meals initiated for water, saccharin, and sucrose was significantly increased, although only the sucrose meals were also significantly increased in size. Others have reported that NPY injections predominantly increased the size of caloric meals more than meal frequency, with the majority of the intake effect expressed in the first meal (Leibowitz \& Alexander, 1991; MarinBivens et al., 1998). It is surprising that NPY did not decidedly decrease the number of meals initiated under sucrose conditions in both experiments, as those meals were vastly prolonged (more than tripled in duration) by NPY. For example, NPY increased meal duration for $0.3 \mathrm{M}$ sucrose from $18 \mathrm{~min}$ to $58 \mathrm{~min}$ in Experiment 1 , dominating the majority of the session. Despite the narrowed opportunity for refeeding, a nonsignificant trend toward an 
A
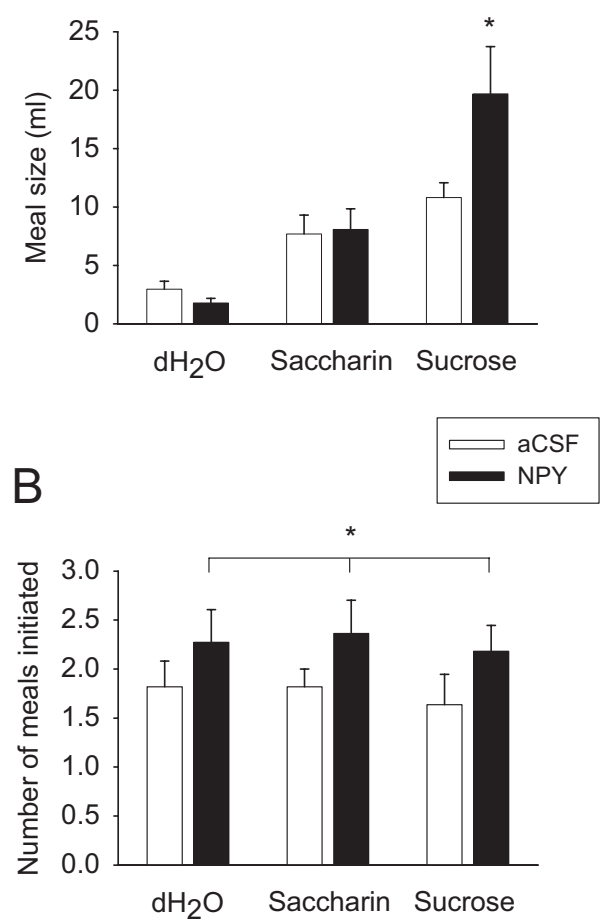

Figure 8. Dissociation of Neuropeptide Y (NPY) effects on meal size and meal frequency. Mean (plus standard error) meal size and number of meals initiated under NPY (filled bars) versus artificial cerebrospinal fluid (aCSF; open bars) conditions for rats ingesting distilled water $\left(\mathrm{dH}_{2} \mathrm{O}\right)$, $0.1 \%$ saccharin, and $1.0 \mathrm{M}$ sucrose. (A) NPY significantly increased meal size for $1.0 \mathrm{M}$ sucrose but not $0.1 \%$ saccharin or water $\left({ }^{*} p<.02\right)$. (B) NPY significantly increased the number of meals initiated for all three taste solutions $(* p<.02)$

increase in meal frequency was also observed in the $1.0 \mathrm{M}$ sucrose condition of Experiment 1, supporting the effect of NPY on appetitive functions, which has been well established by other investigators (Ammar et al., 2000; Day et al., 2005; Sederholm et al., 2002; Seeley, Payne, \& Woods, 1995).

The dissociable effects of NPY on meal size and meal frequency may explain one apparent discrepancy with previous findings for saccharin intake. Lynch et al. (1993) reported that 4-hr intake of $0.05 \%$ saccharin was significantly increased by NPY. ${ }^{1}$ Their $2.5-\mathrm{hr}$ longer test period may have permitted more saccharin meals to be induced by NPY. The current results are consistent with their finding that NPY increased intake for all sucrose solutions tested $(0.06 \mathrm{M}$ to $0.3 \mathrm{M})$ but that it was without effect on 4 -hr water intake. Other studies have reported varied effects of NPY on water intake, depending on the site of NPY injection and whether food was co-available (Corp, Melville, Greenberg, Gibbs, \& Smith, 1990; Lynch et al., 1993; Morley, Levine, Gosnell, Kneip, \& Grace, 1987; Stanley \& Leibowitz, 1984), and our results suggest that NPY effects on water drinking relate to environmental or appetitive rather than consummatory factors.

The effects of NPY on meal size in this study varied as a function of the caloric nature of the tastants used. The failure of NPY to increase saccharin meal size was not due to a lack of hedonic appeal of this solution, because under control conditions saccharin was more preferred than $0.03 \mathrm{M}$ sucrose, whether preference was defined by intake, initial rate of licking, or mean burst size (cf. Tables 1 and 2 and Figures 1 and 7). Our analysis of licking microstructure in the first meal also suggested that NPY's effect depended on a caloric aspect of postingestive feedback signaling rather than gustatory evaluation.

\section{Licking Microstructure}

\section{Measures of Gustatory Evaluation}

We found only limited support for the hypothesis that NPY increases gustatory evaluation. A small but statistically significant increase in the initial rate of licking was observed in Experiment 1, and for $1.0 \mathrm{M}$ sucrose but not saccharin or water in Experiment 2. The failure of NPY to affect water or saccharin initial lick rates indicates that NPY effects at the beginning of the meal were tastant specific and not due to general increases in oromotor activity (see also Figure 2). It is possible that the small initial lick rate increases by NPY were limited by a ceiling effect on behavior at the $1.0 \mathrm{M}$ sucrose conditions. However, this explanation cannot account for the likewise limited increase in initial lick rate under NPY conditions at $0.3 \mathrm{M}$ and particularly $0.03 \mathrm{M}$-sucrose concentrations (see Table 1).

Another measure of gustatory evaluation that is not limited by oromotor ceiling effects is mean burst size (Spector et al., 1998), as was confirmed in the control conditions of Experiment 1 (cf. burst size and initial lick rate measures across concentrations in Table 1 and Figure 5). NPY had little effect on burst sizes for saccharin, water, or the two weaker sucrose concentrations, whereas at the 1.0 M sucrose concentration, NPY significantly reduced mean burst size by half, in both experiments. This result is also consistent with the report that NPY reduced consecutive 10-s bins of licking for $25 \%$ sweetened condensed milk (Lynch et al., 1994).

Reductions in burst size have been observed for naturally aversive tastants such as QHCl (relative to water; Hsiao \& Fan, 1993; Spector \& St. John, 1998) and stimuli to which a CTA has been formed (Baird, St. John, \& Nguyen, 2005). It has been reported that NPY causes CTA, pica, and suppression of need-induced sodium appetite (Madden et al., 1999; Sipols, Brief, Ginter, Saghafi, \& Woods, 1992), but it seems unlikely that the NPY reduction of burst size at $1.0 \mathrm{M}$ sucrose was due to a CTA, for several reasons. First, intake was not suppressed on test days following NPY injection (data not shown). Second, rats had either 2 or 4 days pre-exposure to each tastant before NPY injection, which would be more than adequate to develop latent inhibition (e.g., Kalat \& Rozin, 1973; Turgeon, Auerbach, Duncan-Smith, George, \& Graves, 2000). Third, in Experiment 1, there was no generalization to higher sucrose concentrations under baseline conditions, as would be expected with a CTA (Tapper \& Halpern,

\footnotetext{
${ }^{1}$ It is also worth noting that the effect of NPY on saccharin intake was not reliable. In their first iteration of the experiment, Lynch et al. (1993) noted no effect of NPY on any saccharin concentration tested. They observed a significant effect at this single saccharin concentration only when the study was replicated (see Procedure section in Lynch et al., 1993).
} 
A
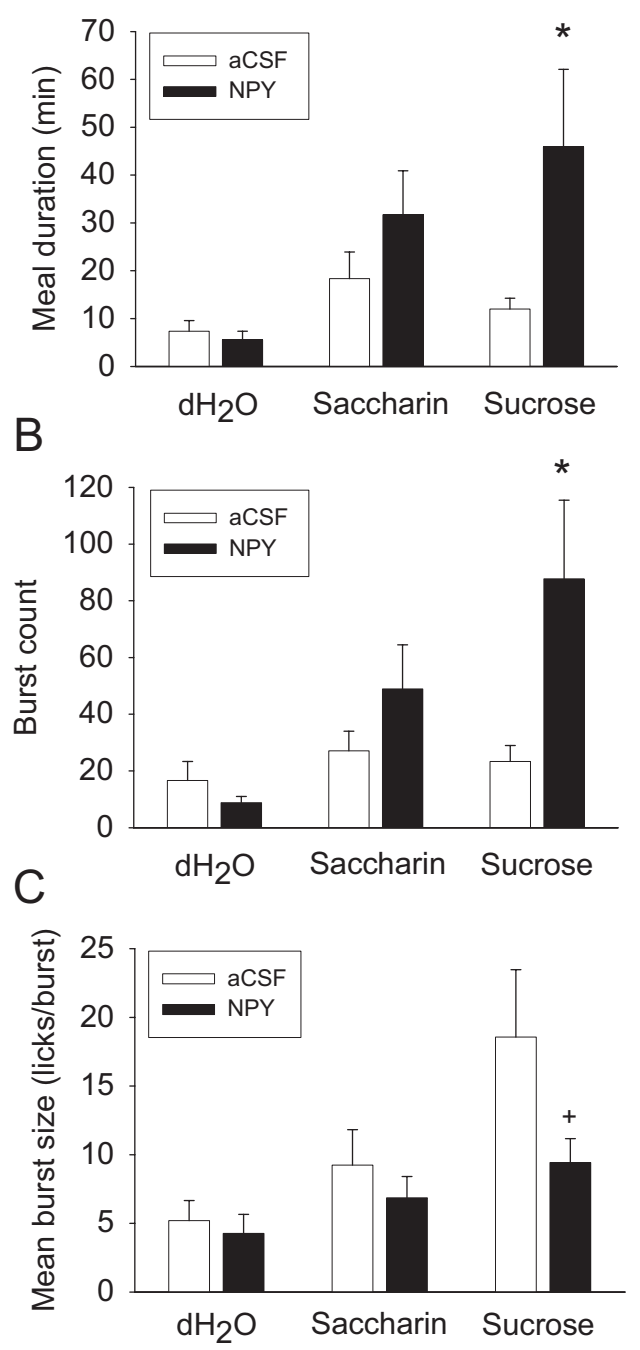

Figure 9. Mean (plus standard error) effects of Neuropeptide Y (NPY; filled bars) on meal duration (min), meal burst count, and mean burst size (licks/burst) versus artificial cerebrospinal fluid (aCSF) conditions (open bars) for rats drinking distilled water $\left(\mathrm{dH}_{2} \mathrm{O}\right), 0.1 \%$ saccharin, and $1.0 \mathrm{M}$ sucrose. (A) NPY had little effect on meal duration for water and $0.1 \%$ saccharin solutions but increased the meal for the $1.0 \mathrm{M}$ sucrose solution more than two-fold $(* p<.05)$. (B) Similarly, NPY failed to affect burst count in either the water or saccharin conditions, but it did significantly increase the number of bursts in $1.0 \mathrm{M}$ sucrose meals $\left({ }^{*} p<.03\right)$. (C) Mean burst size was not affected by NPY treatment for either water or $0.1 \%$ saccharin; however, burst size was marginally reduced in the $1.0 \mathrm{M}$ sucrose condition, relative to aCSF-treated controls $\left({ }^{+} p<.07\right)$.

1968). It is also unclear why an NPY-induced CTA would be limited to $1.0 \mathrm{M}$ sucrose (the only concentration for which NPY reduced burst size) when $0.3 \mathrm{M}$ sucrose and lower concentrations adequately serve as conditioned stimuli for CTA training (e.g., McKay \& Persinger, 2003; Spector, Breslin, \& Grill, 1988). Fifth, CTAs increased the proportions of ILIs ranging from $250 \mathrm{~ms}$ to 1999 ms (Baird, St. John, \& Nguyen, 2005) more than twofold, whereas under NPY no such increases were observed (see Figures
2 and 4B). Finally, ICV NPY at the dose used in this study $(5 \mu \mathrm{g})$ produced a conditioned preference for flavored $0.3 \mathrm{M}$ sucrose (Lynch et al., 1993), one of the concentrations tested in this study. The bases for these discrepancies are unclear; however, it is worth noting that studies reporting a CTA after ICV NPY used a larger dose $(9.5 \mu \mathrm{g})$ and a bitter taste stimulus (unsweetened Kool-Aid; Sipols et al., 1992). Indeed, when sweetened Kool-Aid was used as a conditioned stimulus, rats formed a conditioned preference for it after exposure to NPY (Lynch et al., 1993).

Overall, it is clear that NPY affected burst initiation processes (engaging the spout), as the number of bursts in sucrose meals was roughly quadrupled by NPY. The results also suggest that NPY influenced burst termination processes in a manner consistent with an effect of NPY to set an upper limit on burst size. Although the sizes of bursts increased across sucrose concentrations under baseline aCSF conditions, burst sizes under NPY at $1.0 \mathrm{M}$ sucrose were leveled off and comparable to those for 0.3 M sucrose (see Figure 4A). It is alluring to speculate that NPY induces a particular type of behavior (perhaps foraging) to cause bursts to terminate after a certain maximal amount of time or number of licks; however, our analysis of pauses under NPY (Figure 4) suggests that no one type of behavior/pause occurred with more relative frequency to cause bursts to terminate prematurely under NPY.

\section{Measures of Postingestive Feedback}

Other measures of licking microstructure provided more consistent support for the hypothesis that NPY produced a diminution of inhibitory postingestive feedback. The rate of licking in the first 5 min was significantly faster under NPY conditions for the two highest concentrations of sucrose tested in Experiment 1, and a similar, albeit nonsignificant, trend was observed for $1.0 \mathrm{M}$ sucrose conditions in Experiment 2. Analysis by meal thirds indicated that NPY did not straightforwardly increase ingestion rate (vertically shifting lick rate); rather, NPY expanded the range of ingestion rates expressed across the meal, as manifested by a faster rate of licking early in the meal and a much slower but sustained ingestion rate toward its end, greatly prolonging the meal as a whole. For example, in Figure $6 \mathrm{~B}$, as $0.3 \mathrm{M}$ sucrose meals entered the last third, rats under control conditions licked at a rate comparable to the middle of the meal $(1.0 \mathrm{ml} / \mathrm{min})$, whereas the same rats under NPY conditions ingested at a much slower rate $(0.4$ $\mathrm{ml} / \mathrm{min})$.

Studies show that diminishing inhibitory feedback from the gut, such as through sham feeding via an open gastric fistula or through food deprivation, tends to increase ingestion rate, reduce the rate of decline in ingestion rate, increase burst count, and prolong meal duration (Smith, 1998; see also Davis, 1998; Davis \& Campbell, 1973; Davis \& Levine, 1977; Davis et al., 1994, 1995, 1997; Eisen et al., 2001; G. J. Schwartz et al., 1999; Spector et al., 1998). The expansion of ingestion rate range, increase in burst count, and prolonging of the meal by NPY here is consistent with the hypothesis that NPY reduces the inhibitory impact of the postingestive load.

\section{Effects of NPY on Intraoral Intake}

Several studies have reported that NPY fails to increase intraoral intake, a model of consummatory behavior (Ammar et al., 2000; 
Benoit et al., 2005; Sederholm et al., 2002; Seeley, Payne, \& Woods, 1995), leading to the logical conclusion that NPY effects are limited to appetitive functions. Investigators have alternatively suggested that NPY fails to increase intraoral intake due to training regimen and baseline intake values in the intraoral intake tests (Benoit et al., 2005). However, this study shows that NPY increased both consummatory (increasing licking within meals) and appetitive (increasing meal initiations) behaviors. Thus, another insight into this curious non-effect of NPY is provided by our finding that NPY expanded the range of ingestion rates. For example, the ingestion rate for $0.3 \mathrm{M}$ sucrose under baseline conditions declined to $1.0 \mathrm{ml} / \mathrm{min}$ by the last meal third, whereas under NPY, it declined to $0.4 \mathrm{ml} / \mathrm{min}$. In the intraoral intake test, tastants are infused directly into the mouth at a constant rate (usually $1.0 \mathrm{ml} / \mathrm{min}$ ) until solution is actively expelled or passively drips from the mouth; thus, the ingestion rate is clamped to the rate set by the experimenter. It is possible that the intraoral tests with fixed rates do not capture reductions in ingestion rate to a very slow pace, resulting in premature intraoral meal termination.

It is important to note, however, that rats can aptly maintain relatively constant meal sizes across a range of intraoral infusion rates (0.5 to $1.5 \mathrm{ml} / \mathrm{min}$; Kaplan, Spector, \& Grill, 1990) and spout lick volumes (2-8 $\mu$ l; Kaplan et al., 2001; Kaplan, Donahey, Baird, Simansky, \& Grill, 1997). Furthermore, NPY has no intraoral intake effect with intraoral infusion rates ranging from 0.5 to $1.5 \mathrm{ml} / \mathrm{min}$ (Ammar et al., 2000; Sederholm et al., 2002; Seeley, Payne, \& Woods, 1995). Nevertheless, variations of the flow rate within the test session have not been tested under NPY conditions. Indeed, Kaplan et al. (1990) observed that rats resumed intraoral ingestion of $1.0 \mathrm{M}$ or $0.1 \mathrm{M}$ sucrose after an initial fluid rejection if the infusion was reinstated at a slower rate and that cumulative intake was significantly greater when rats were switched from an ingestion rate of $1.5 \mathrm{ml} / \mathrm{min}$ in the first phase to $0.5 \mathrm{ml} / \mathrm{min}$ in the latter phase of the meal, rates that are comparable to those we observed under NPY conditions.

\section{Comparison With the Effects of Food Deprivation}

Several investigators have explored the attractive hypothesis that NPY administration evokes a state akin to food deprivation. This notion receives indirect support from several studies showing that food deprivation and scheduled feeding increases hypothalamic NPY mRNA and protein (e.g., Brady, Smith, Gold, \& Herkenham, 1990; M. W. Schwartz, Sipols, Grubin, \& Baskin, 1993). Elegant instrumental techniques have also been used to explore this hypothesis, but, to date, opposing outcomes and interpretations have been reported. Jewett, Cleary, Levine, Schaal, and Thompson (1995) showed that NPY produced break points in lever pressing for food on a progressive ratio schedule that were comparable to those induced by $36-$ to $48-\mathrm{hr}$ food deprivation; others found that NPY treatment failed to generalize to conditions previously paired with 24-hr food deprivation in a behavioral freezing paradigm (Seeley, Benoit, \& Davidson, 1995). Recently, it was reported that NPY and 12-hr or 24-hr food deprivation increased intake via comparable increases primarily in meal size, with smaller but significant increases also in meal frequency (Marin-Bivens et al., 1998).

The current study offers a means to extend these efforts through a comparison with studies that have evaluated the effects of food deprivation on licking microstructure. The clearest effects of NPY on licking in this study were increases in meal duration, burst count, and the range of ingestion rates expressed during the meal. Davis and Perez (1993) and Spector et al. (1998) determined that 17-hr or 23.5-hr food deprivation increased meal sizes and burst counts for 0.05 to $1.0 \mathrm{M}$ sucrose concentrations, with deprivationinduced increases in ingestion rate also observed at various sucrose concentrations. Overall, it appears that NPY and food deprivation treatments increase meal size through comparable effects on licking microstructure. It should be noted that food deprivation was reported to increase intraoral intake, whereas NPY did not (Seeley, Payne, \& Woods, 1995). However, this deprivation effect was not replicated (Ammar et al., 2000; Mamoun, Anderstam, Bergstrom, Qureshi, \& Sodersten, 1995; Mamoun, Bergstrom, \& Sodersten, 1997), which also suggests that the intraoral intake test may not capture all of the consummatory influences of NPY and food deprivation on ingestive behavior.

\section{Limitations}

Some results of this study must be qualified. Our conclusion that the meal-size effects of NPY are limited to caloric stimuli could be strengthened by testing the effects of NPY on consumption of other preferred noncaloric tastants or after explicit gastrointestinal treatments. Also, the current data are not conclusive with regard to the effects of NPY on taste evaluation, though overall these data do not suggest a significant effect of NPY on taste evaluation, which is consistent with the finding that NPY failed to increase ingestive oromotor movements (taste reactivity) to brief intraoral infusions of water or sucrose solutions (Sederholm et al., 2002; see also Berridge, 2000). Although NPY may not mediate meal size increases through a modulation of taste evaluation per se, it is possible that NPY meal effects are limited either to preferred tastants or those lacking aversive oral properties, as saccharin evokes both bitter and sweet qualities in rats and humans (Dess, 1993). This interpretation is consistent with reports that NPY selectively increased intake of polycose- and sucrose-enriched diets, but not cornstarch-enriched diets (Glass, Cleary, Billington, \& Levine, 1997), that NPY no longer increased approaches to a bottle after a quantity of $3 \mathrm{mM} / \mathrm{L} \mathrm{QHCl}$ was added to a sucrose solution (Sederholm et al., 2002), and that $6 \mathrm{mM} / \mathrm{L} \mathrm{QHCl}$ added to a milk solution suppressed increases in lever pressing for solution access induced by a low dose of NPY (Flood \& Morley, 1991).

The broad reach of the forebrain ICV NPY injections used in this study undoubtedly stimulated multiple NPY-sensitive systems involved in multiple functions. Our detailed analysis of behavior indeed revealed multiple, dissociable effects of NPY on feeding behaviors, and it will be important in future studies to determine whether any or all of these feeding effects are differentially affected when NPY stimulation is varied across a range of doses and is limited to more restricted anatomical sites and NPY receptor subsystems. We speculate that the meal frequency effects of NPY might be lost when NPY infusions are limited to the hindbrain: Chronic decerebrate rats with severed forebrain connections show a loss of appetitive but not consummatory functions (Grill, 1980), whereas forebrain infusions of NPY increase exploratory behavior and meal frequency (Leibowitz \& Alexander, 1991; Marin-Bivens et al., 1998; Morley, Levine, Gosnell, Kneip, \& Grace, 1987; Smialowski, Lewinska-Gastol, \& Smialowska, 1992). Moreover, 
fourth ventricular or NPY infusions into the nucleus of the solitary tract have no effect on exploratory behavior (Corp et al., 1990) but do affect gastric motility (Chen, Stephens, \& Rogers, 1997; Kobashi et al., 2006). Numerous connections between forebrain and hindbrain NPY sites have been identified, notably between hypothalamic arcuate nucleus NPY neurons and the hypothalamic paraventricular nucleus, the lateral hypothalamus, and the lateral parabrachial nucleus in the hindbrain (Broberger, Johansen, Johansson, Schalling, \& Hokfelt, 1998). In addition, ICV injections of NPY at the same dose used in this study evoked c-fos immunoreactivity in hypothalamic paraventricular nucleus and perifornical hypothalamus neurons identified to directly project to the spinal cord and to the dorsal vagal complex, encompassing the nucleus of the solitary tract, area postrema, and dorsal motor nucleus of the vagus (Vinuela \& Larsen, 2001; see also Gray, O’Donohue, \& Magnuson, 1986).

\section{Perspectives: Appetitive Versus Consummatory Definitions}

To this point in this article we have treated the distinction between appetitive and consummatory behaviors as one that is generally meal defined: Consummatory behaviors are those exhibited within the meal, whereas appetitive behaviors can be considered a subgroup of behaviors that occur between meals (e.g., foraging). Although commonly used (e.g., Day et al., 2005; Zheng et al., 2005). This distinction is subject to alternative interpretations. By the most conservative definition, any bottle-drinking behaviors other than licking and swallowing, that is, those producing pauses between licking bursts, could be defined in a strict sense to be "appetitive," as they do not deliver food to the oral cavity or to the gut. ${ }^{2}$ From this perspective, the NPY-induced increase in burst count may be considered an "appetitive" effect, and, further, NPY's failure to increase the mean size of licking bursts may be considered to indicate that it had no "consummatory" effect. However, this definition is also imperfect: Ingestive oromotor responses such as serial tongue protrusions can give rise to brief pauses in licking that last 1 to $2 \mathrm{~s}$ or more (unpublished observations), and rats exhibit many bursts and pauses while remaining stationary at the spout (Davis, 1998) or during intraoral infusions (Kaplan et al., 1995). Additionally, food deprivation and gastric preloads, treatments that clearly affect consummatory feeding (specifically, intraoral intake and meal size in bottle tests; G. J. Schwartz et al., 1999; Seeley, Grill, \& Kaplan, 1994; Seeley, Payne, \& Woods, 1995) more commonly affect the number of bursts in a meal rather than mean burst size (Davis \& Perez, 1993; Eisen et al., 2001; Grill, Roitman, \& Kaplan, 1996; Spector et al., 1998).

Nevertheless, using an alternative approach, we attempted to further titrate the consummatory effects of NPY with a meal criterion analysis. Using the $1.0 \mathrm{M}$ sucrose condition in Experiment 1 , we applied successively shorter meal-ending pause criteria to the lick count data to determine at what point the effect of NPY effect on consumption was lost. NPY significantly increased intake before the expression of any pauses $30 \mathrm{~s}$ or greater, and it more than doubled intake for at least some rats even before the first 3-s pause in the meal (see Figure 10). Furthermore, it should be recalled that NPY significantly increased the number of licks in the 1 st through the 5 th min of the meal, when ingestion rate was near

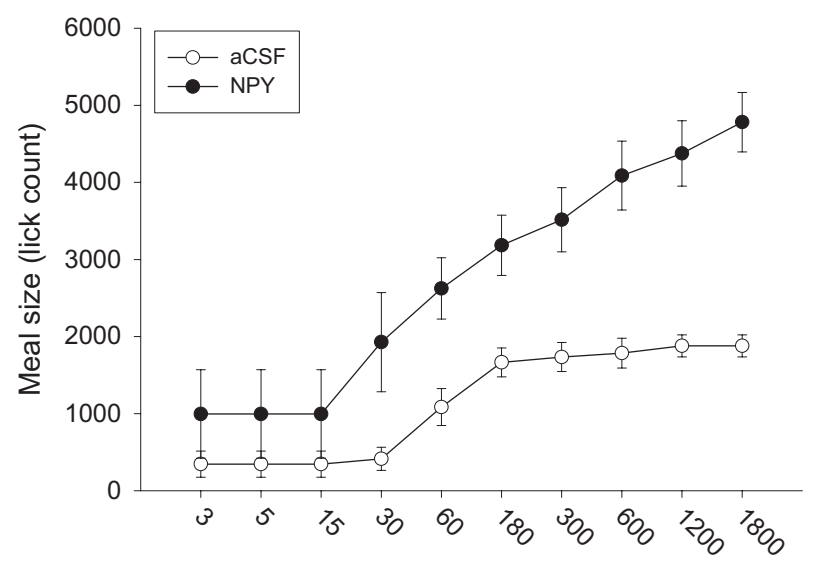

Meal-ending pause criterion (s)

Figure 10. Effects of NPY across different meal termination criteria. The mean number of licks (plus or minus standard error) emitted for the $1.0 \mathrm{M}$ sucrose solution prior to the expression of a pause equal to or greater than the meal-ending pause criterion value (indicated on the abscissa) is plotted for artificial cerebrospinal fluid (aCSF; open circles) and Neuropeptide Y (NPY; filled circles) conditions. NPY significantly doubled meal size when meal criteria as brief as $30 \mathrm{~s}$ were used, $F(1,18)=6.36, p<.04$, and a more-than-double but nonsignificant intake increase by NPY was also observed when the criterion was as small as $3 \mathrm{~s}(p=.12)$. In other words, NPY significantly increased the number of licks exhibited prior to the first pause $30 \mathrm{~s}$ or greater in duration, relative to control conditions.

maximal at 1.0 M sucrose concentrations and long pauses were most unlikely (see Figure 5). Taken together, these results support the interpretation that NPY can increase fluid consumption independently of increases in appetitive behavior. Nevertheless, more conclusive proof could be provided by a detailed videographic analysis of NPY effects.

\section{Postscript}

During processing of this article, Torregrossa, Davis, and Smith (2006) reported that NPY increased sham feeding, indicating that NPY need not subdue post-ingestive negative feedback in order to increase intake. Their results are consistent with and reinforce our finding that NPY treatment affects a multitude of dissociable appetitive and consummatory feeding processes.

\footnotetext{
${ }^{2}$ In his landmark paper, Craig (1918) stated that consummatory behavior is an innate reaction to an "appeted" stimulus, which terminates a state of agitation that occurred preceding acquisition of the stimulus and that it is followed "by a state of relative rest" (p. 91). This definition can be applied to feeding behavior in different time frames, for example, to bursts of licking and the pauses that follow them or to meals and the sequences of behaviors between them. We believe that the interpretation that consummatory behaviors are those that deliver food to the oral cavity and to the gut is consistent with Craig's perspective that consummatory reactions are reflexive in nature.
}

\section{References}

Ammar, A. A., Nergardh, R., \& Fredholm, B. B., Brodin, U., \& Sodersten, P. (2005). Intake inhibition by NPY and CCK-8: A challenge of the 
notion of NPY as an "orexigen." Behavioural Brain Research, 161, $82-87$.

Ammar, A. A., Sederholm, F., Saito, T. R., Scheurink, A. J., Johnson, A. E., \& Sodersten, P. (2000). NPY-leptin: Opposing effects on appetitive and consummatory ingestive behavior and sexual behavior. American Journal of Physiology: Regulatory, Integrative and Comparative Physiology, 278, R1627-R1633.

Baird, J. P., Kaplan, J. M., \& Grill, H. J. (1999). Effect of hepatic glucose infusion on glucose intake and licking microstructure in deprived and nondeprived rats. American Journal of Physiology, 277, R1136-R1143.

Baird, J. P., St. John, S. J., \& Nguyen, E. A. (2005). Temporal and qualitative dynamics of conditioned taste aversion processing: Combined generalization testing and licking microstructure analysis. Behavioral Neuroscience, 119, 983-1003.

Benoit, S. C., Clegg, D. J., Woods, S. C., \& Seeley, R. J. (2005). The role of previous exposure in the appetitive and consummatory effects of orexigenic neuropeptides. Peptides, 26, 751-757.

Berridge, K. C. (2000). Measuring hedonic impact in animals and infants: Microstructure of affective taste reactivity patterns. Neuroscience and Biobehavioral Reviews, 24, 173-198.

Brady, L. S., Smith, M. A., Gold, P. W., \& Herkenham, M. (1990). Altered expression of hypothalamic neuropeptide mRNAs in food-restricted and food-deprived rats. Neuroendocrinology, 52, 441-447.

Broberger, C., Johansen, J., Johansson, C., Schalling, M., \& Hokfelt, T. (1998). The neuropeptide Y/agouti gene-related protein (AGRP) brain circuitry in normal, anorectic, and monosodium glutamate-treated mice. Proceedings of the National Academy of Sciences U S A, 95, 1504315048.

Chen, C. H., Stephens, R. L., Jr., \& Rogers, R. C. (1997). PYY and NPY: Control of gastric motility via action on $\mathrm{Y} 1$ and $\mathrm{Y} 2$ receptors in the DVC. Neurogastroenterology \& Motility, 9, 109-116.

Corp, E. S., Melville, L. D., Greenberg, D., Gibbs, J., \& Smith, G. P. (1990). Effect of fourth ventricular neuropeptide $Y$ and peptide $Y Y$ on ingestive and other behaviors. American Journal of Physiology, 259, R317-R323.

Craig, W. (1918). Appetites and aversions as constituents of instincts. Biological Bulletin of Woods Hole, 34, 91-107.

Davis, J. D. (1996). Deterministic and probabilistic control of the behavior of rats ingesting liquid diets. American Journal of Physiology, 270, R793-R800.

Davis, J. D. (1998). A model for the control of ingestion-20 years later. Progress in Psychobiology and Physiological Psychology, 17, 127-173.

Davis, J. D., \& Campbell, C. S. (1973). Peripheral control of meal size in the rat: Effect of sham feeding on meal size and drinking rate. Journal of Comparative and Physiological Psychology, 83, 379-387.

Davis, J. D., \& Levine, M. W. (1977). A model for the control of ingestion. Psychological Review, 84, 379-412.

Davis, J. D., \& Perez, M. C. (1993). Food deprivation- and palatabilityinduced microstructural changes in ingestive behavior. American Journal of Physiology, 264, R97-R103.

Davis, J. D., \& Smith, G. P. (1992). Analysis of the microstructure of the rhythmic tongue movements of rats ingesting maltose and sucrose solutions. Behavioral Neuroscience, 106, 217-228.

Davis, J. D., Smith, G. P., \& Kung, T. M. (1994). Abdominal vagotomy alters the structure of the ingestive behavior of rats ingesting liquid diets. Behavioral Neuroscience, 108, 767-779.

Davis, J. D., Smith, G. P., \& Kung, T. M. (1995). Abdominal vagotomy attenuates the inhibiting effect of mannitol on the ingestive behavior of rats. Behavioral Neuroscience, 109, 161-167.

Davis, J. D., Smith, G. P., \& Sayler, J. L. (1997). Reduction of intake in the rat due to gastric filling. American Journal of Physiology, 272, R1599R1605.

Davis, J. D., Smith, G. P., \& Sayler, J. L. (1998). Closing the pylorus decreases the size of large meals in the rat. Physiology \& Behavior, 63, 191-196.

Day, D. E., Keen-Rhinehart, E., \& Bartness, T. J. (2005). Role of NPY and its receptor subtypes in foraging, food hoarding, and food intake by Siberian hamsters. American Journal of Physiology: Regulatory, Integrative and Comparative Physiology, 289, R29-R36.

Dess, N. K. (1993). Saccharin's aversive taste in rats: Evidence and implications. Neuroscience and Biobehavioral Reviews, 17, 359-372.

Eisen, S., Davis, J. D., Rauhofer, E., \& Smith, G. P. (2001). Gastric negative feedback produced by volume and nutrient during a meal in rats. American Journal of Physiology: Regulatory, Integrative and Comparative Physiology, 281, R1201-R1214.

Flaherty, C. F., Coppotelli, C., Grigson, P. S., Mitchell, C., \& Flaherty, J. E. (1995). Investigation of the devaluation interpretation of anticipatory negative contrast. Journal of Experimental Psychology: Animal Behavior Processes, 21, 229-247.

Flood, J. F., \& Morley, J. E. (1991). Increased food intake by Neuropeptide $\mathrm{Y}$ is due to an increased motivation to eat. Peptides, 12, 1329-1332.

Glass, M. J., Cleary, J. P., Billington, C. J., \& Levine, A. S. (1997). Role of carbohydrate type on diet selection in NeuropeptideY-stimulated rats. American Journal of Physiology, 273, R2040-R2045.

Gray, T. S., O’Donohue, T. L., \& Magnuson, D. J. (1986). Neuropeptide Y innervation of amygdaloid and hypothalamic neurons that project to the dorsal vagal complex in rat. Peptides, 7, 341-349.

Grill, H. J. (1980). Production and regulation of ingestive consummatory behavior in the chronic decerebrate rat. Brain Research Bulletin, 5, $79-87$.

Grill, H. J., Roitman, M. F., \& Kaplan, J. M. (1996). A new taste reactivity analysis of the integration of taste and physiological state information. American Journal of Physiology, 271, R677-R687.

Hsiao, S., \& Fan, R. J. (1993). Additivity of taste-specific effects of sucrose and quinine: Microstructural analysis of ingestive behavior in rats. Behavioral Neuroscience, 107, 317-326.

Jewett, D. C., Cleary, J., Levine, A. S., Schaal, D. W., \& Thompson, T. (1995). Effects of Neuropeptide Y, insulin, 2-deoxyglucose, and food deprivation on food-motivated behavior. Psychopharmacology, 120, 267-271.

Kalat, J. W., \& Rozin, P. (1973). "Learned safety" as a mechanism in long-delay taste-aversion learning in rats. Journal of Comparative and Physiological Psychology, 83, 198-207.

Kaplan, J. M., Baird, J. P., \& Grill, H. J. (2001). Dissociation of licking and volume intake controls in rats ingesting glucose and maltodextrin. Behavioral Neuroscience, 115, 188-195.

Kaplan, J. M., Donahey, J., Baird, J. P., Simansky, K. J., \& Grill, H. J. (1997). D-fenfluramine anorexia: Dissociation of ingestion rate, meal duration, and meal size effects. Pharmacology, Biochemistry, \& Behavior, 57, 223-229.

Kaplan, J. M., Roitman, M. F., \& Grill, H. J. (1995). Ingestive taste reactivity as licking behavior. Neuroscience and Biobehavioral Reviews, 19, 89-98.

Kaplan, J. M., Siemers, W., \& Grill, H. J. (1994). Ingestion, gastric fill, and gastric emptying before and after withdrawal of gastric contents. American Journal of Physiology, 267, 1257-1265.

Kaplan, J. M., Spector, A. C., \& Grill, H. J. (1990). Ingestion rate as an independent variable in the behavioral analysis of satiation. American Journal of Physiology, 258, R662-R671.

Kobashi, M., Shimatani, Y., Shirota, K., Xuan, S. Y., Mitoh, Y., \& Matsuo, R. (2006). Central Neuropeptide Y induces proximal stomach relaxation via Y1 receptors in the dorsal vagal complex of the rat. American Journal of Physiology: Regulatory, Integrative and Comparative Physiology, 290, R290-297.

Kowalski, T. J., Farley, C. Cohen-Williams, M. E., Varty, G., \& Spar, B. D. (2004). Melanin-concentrating hormone-1 receptor antagonism 
decreases feeding by reducing meal size. European Journal of Pharmacology, 497, 41-47.

Leibowitz, S. F., \& Alexander, J. T. (1991). Analysis of Neuropeptide Y-induced feeding: Dissociation of Y1 and Y2 receptor effects on natural meal patterns. Peptides, 12, 1251-1260.

Lynch, W. C., Grace, M., Billington, C. J., \& Levine, A. S. (1993). Effects of neuropeptide $\mathrm{Y}$ on ingestion of flavored solutions in nondeprived rats. Physiology \& Behavior, 54, 877-880.

Lynch, W. C., Hart, P., \& Babcock, A. M. (1994). Neuropeptide Y attenuates satiety: Evidence from a detailed analysis of patterns ingestion. Brain Research, 636, 28-34.

Madden, L. J., Seeley, R. J., \& Woods, S. C. (1999). Intraventricular neuropeptide $\mathrm{Y}$ decreases need-induced sodium appetite and increases pica in rats. Behavioral Neuroscience, 113, 826-832.

Mamoun, A. H., Anderstam, B., Bergstrom, J., Qureshi, G. A., \& Sodersten, P. (1995). Diet-independent suppression of ingestive behavior by cholecystokinin octapeptide and amino acids. American Journal of Physiology: Regulatory, Integrative and Comparative Physiology, 268, R520-R527.

Mamoun, A. H., Bergstrom, J., \& Sodersten, P. (1997). Cholecystokinin octapeptide inhibits carbohydrate but not protein intake. American Journal of Physiology: Regulatory, Integrative and Comparative Physiology, 273, R972-R980.

Marin-Bivens, C. L., Thomas, W. J., \& Stanley, B. G. (1998). Similar feeding patterns are induced by perifornical neuropeptide $\mathrm{Y}$ injection and by food deprivation. Brain Research, 782, 271-280.

McKay, B. E., \& Persinger, M. A. (2003). Conditioned taste aversion is not disrupted in rats exposed to weak, complex magnetic fields during the CS-UCS interval. Perceptual Motor Skills, 97, 1335-1338.

Morley, J. E., Levine, A. S., Gosnell, B. A., Kneip, J., \& Grace, M. (1987). Effect of Neuropeptide $\mathrm{Y}$ on ingestive behaviors in the rat. American Journal of Physiology, 252, R599-R609.

Schwartz, G. J., \& Moran, T. H. (2002). Leptin and Neuropeptide Y have opposing modulatory effects on nucleus of the solitary tract neurophysiological responses to gastric loads: Implications for the control of food intake. Endocrinology, 143(10), 3779-3884.

Schwartz, G. J., Salorio, C. F., Skoglund, C., \& Moran, T. H. (1999). Gut vagal afferent lesions increase meal size but do not block gastric preload-induced feeding suppression. American Journal of Physiology, 276, R1623-R1629.

Schwartz, M. W., Sipols, A. J., Grubin, C. E., \& Baskin, D. G. (1993). Differential effect of fasting on hypothalamic expression of genes encoding Neuropeptide Y, galanin, and glutamic acid decarboxylase. Brain Research Bulletin, 31, 361-367.

Sederholm, F., Ammar, A. A., \& Sodersten, P. (2002). Intake inhibition by NPY: Role of appetitive ingestive behavior and aversion. Physiology \& Behavior, 75, 567-575.

Seeley, R. J., Benoit, S. C., \& Davidson, T. L. (1995). Discriminative cues produced by NPY do not generalize to the interoceptive cues produced by food deprivation. Physiology \& Behavior, 58, 1237-1241.

Seeley, R. J., Grill, H. J., \& Kaplan, J. M. (1994). Neurological dissociation of gastrointestinal and metabolic contributions to meal size control. Behavioral Neuroscience, 108, 347-352.

Seeley, R. J., Payne, C. J., \& Woods, S. C. (1995). Neuropeptide Y fails to increase intraoral intake in rats. American Journal of Physiology, 268, R423-R427.

Sipols, A. J., Brief, D. J., Ginter, K. L., Saghafi, S., \& Woods, S. C. (1992).
Neuropeptide Y paradoxically increases food intake yet causes conditioned flavor aversions. Physiology \& Behavior, 51, 1257-1260.

Smialowski, A., Lewinska-Gastol, L., \& Smialowska, M. (1992). The behavioural effects of Neuropeptide Y (NPY) injection into the rat brain frontal cortex. Neuropeptides, 21, 153-156.

Smith, G. P. (1998). Satiation: From gut to brain. New York: Oxford University Press.

Spector, A. C., Breslin, P., \& Grill, H. J. (1988). Taste reactivity as a dependent measure of the rapid formation of conditioned taste aversion: A tool for the neural analysis of taste-visceral associations. Behavioral Neuroscience, 102, 942-952.

Spector, A. C., Klumpp, P. A., \& Kaplan, J. M. (1998). Analytical issues in the evaluation of food deprivation and sucrose concentration effects on the microstructure of licking behavior in the rat. Behavioral Neuroscience, 112, 678-694.

Spector, A. C., \& St. John, S. J. (1998). Role of taste in the microstructure of quinine ingestion by rats. American Journal of Physiology, 274, R1687-R1703.

Stanley, B. G., \& Leibowitz, S. F. (1984). Neuropeptide Y: Stimulation of feeding and drinking by injection into the paraventricular nucleus. Life Sciences, 35, 2635-2642.

Tapper, D. N., \& Halpern, B. P. (1968). Taste stimuli: A behavioral categorization. Science, 161, 708-710.

Thomson, H. J., Geoghegan, J. G., Farouk, M., Saperstein, L. A., Chung, K., Meyers, W. C., \& Pappas, T. N. (1993). Exogenous Neuropeptide Y blocks myoelectric activity in the upper gastrointestinal tract of starved dogs: Brain neuropeptide Y converts a fasting pattern of myoelectric activity to a fed pattern. Scandinavian Journal of Gastroenterology, 2, 469-474.

Torregrossa, A.-M., Davis, J. D., \& Smith, G. P. (2006). Orosensory stimulation is sufficient and postingestive feedback is not necessary for neuropeptide Y to increase sucrose intake. Physiology \& Behavior, 87, 773-780.

Travers, J. B., Dinardo, L. A., \& Karimnamazi, H. (1997). Motor and premotor mechanisms of licking. Neuroscience Biobehavioral Reviews, 21, 631-647.

Turgeon, S. M., Auerbach, E. A., Duncan-Smith, M. K., George, J. R., \& Graves, W. W. (2000). The delayed effects of DTG and MK-801 on latent inhibition in a conditioned taste-aversion paradigm. Pharmacology, Biochemistry, \& Behavior, 66, 533-539.

Vinuela, M. C., \& Larsen, P. J. (2001). Identification of NPY-induced c-fos expression in hypothalamic neurones projecting to the dorsal vagal complex and the lower thoracic spinal cord. Journal of Comparative Neurology, 438, 286-299.

Zheng, H., Patterson, L. M., Phifer, C. B., \& Berthoud, H. R. (2005). Brain stem melanocortinergic modulation of meal size and identification of hypothalamic POMC projections. American Journal of Physiology: Regulatory, Integrative and Comparative Physiology, 289, R247-R258.

Zorrilla, E. P., Inoue, K., Fekete, E. M., Tabarin, A., Valdez, G. R., \& Koob, G. F. (2005). Measuring meals: Structure of prandial food and water intake of rats. American Journal of Physiology: Regulatory, Integrative and Comparative Physiology, 288, R1450-R1467.

Received January 9, 2006 Revision received April 11, 2006 Accepted April 17, 2006 